INEEL/EXT-2000-01367

January 2001

\title{
Qualitative Reliability Issues for Solid and Liquid Wall Fusion Designs
}

L. C. Cadwallader 


\title{
Qualitative Reliability Issues for Solid and Liquid Wall Fusion Designs
}

\author{
Lee C. Cadwallader
}

Published January 2001

Idaho National Engineering and Environmental Laboratory Nuclear Engineering Development and Research Department Idaho Falls, Idaho 83415

Prepared for the

U.S. Department of Energy

Office of Fusion Energy Sciences

Under DOE Idaho Operations Office

Contract DE-AC07-99ID13727 


\section{ABSTRACT}

This report is an initial effort to identify issues affecting reliability and availability of solid and liquid wall designs for magnetic fusion power plant designs. A qualitative approach has been used to identify the possible failure modes of major system components and their effects on the systems. A general set of design attributes known to affect the service reliability has been examined for the overview solid and liquid wall designs, and some specific features of good first wall design have been discussed and applied to these designs as well. The two generalized designs compare well in regard to these design attributes. The strengths and weaknesses of each design approach are seen in the comparison of specific features. 


\section{SUMMARY}

Some members of the magnetic fusion community have suggested that conventional solid wall armor for magnetic fusion is not reliable enough to make the overall fusion plant economically attractive, and they have suggested design alternatives such as liquid self-renewing walls. Other members of the magnetic fusion community believe that strides have been made in solid walls and are dubious of the technical feasibility of liquid walls. Such feasibility issues may not be overcome even if the overall availability of liquid wall systems were greater than that of conventional solid walls. A quantitative analysis of the availability of these two approaches cannot be performed because there is inadequate design detail at the present time. A preliminary qualitative examination of the reliability issues associated with solid and liquid walls can be useful to help understand the strengths and weaknesses of each approach, and to highlight areas for further study.

This report presents a preliminary examination of qualitative reliability issues of solid wall and liquid wall fusion designs. A comparative failure modes and effects analysis (FMEA) approach was used to identify the different reliability issues for the two design concepts. Very generalized designs were used for the evaluation. Using the results of the FMEA method, the following eight issues of importance were identified: coolant pump reliability, vacuum quality, liquid wall nozzle reliability, maintenance downtime issues, responses to loss of vacuum accidents (that is, vacuum component failures), responses to loss of coolant accidents (that is, piping failures), helium pumping ability for vacuum cleanliness, and natural circulation of reactor coolant.

There are vast differences in system design approaches at the first wall. In solid wall designs, the in-vessel system consists of large wall modules with cooling passages (such as the $\mathrm{SiC}$ passages in advanced tokamak designs), headers, and module mounts. In liquid wall designs, the first wall is an open surface, and the remainder of the in-vessel system consists of a small number of flow nozzles, flow vanes, and electrically insulated substrate plates. This trade-off initially appears to be very positive since the number of components and their complexity are greatly reduced. However, the overall availability of the liquid wall system is now determined not by passive component wall modules, but the active pump component. Thus, for liquid wall systems, the overall availability is determined by the flow loop. Of course, the solid wall systems need operating pumps as well to allow system operation, but the consequences of an offnormal flow event are less severe for low afterheat solid walls since the solid wall modules are designed for replacement if they are damaged.

Table S-1 shows how this initial list of important features compared between designs. The comparison highlights these reliability issues; some can be changed by design. Others may be altered by feedback from testing. The remainder of the liquid wall flow system must be designed and analyzed for reliability in design before numerical comparisons of plant availability are made. The liquid wall idea should be investigated for its merits, and for the possibility of use in conjunction with solid walls, as in the Advanced Limiter-divertor Plasma facing Systems (ALPS) task. 
Table S-1. Comparison of Reliability Features of Interest

\begin{tabular}{|l|c|c|}
\hline \multicolumn{1}{|c|}{ Feature } & Solid wall & Liquid wall \\
\hline Coolant pumping & + & $?$ \\
\hline Vacuum quality & + & $?$ \\
\hline Nozzle reliability & - & + \\
\hline Maintenance downtime & - & - \\
\hline LOVAs & - & - \\
\hline LOCAs & + & $?$ \\
\hline Helium pumping & + & - \\
\hline Natural circulation & & $?$ \\
\hline
\end{tabular}

legend: + indicates good, / is neutral, - is poor, and ? indicates unknown at this time 


\section{CONTENTS}

ABSTRACT iii

SUMMARY .iv

ACRONYMS vii

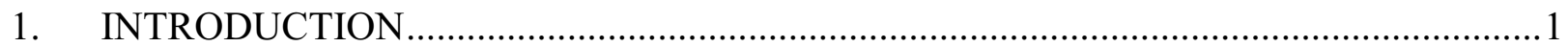

2. OVERVIEW OF LIQUID AND SOLID WALL CONCEPTUAL DESIGNS ....................2

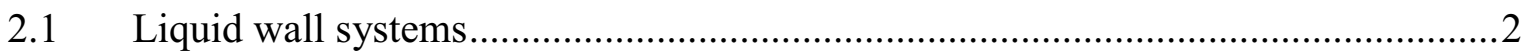

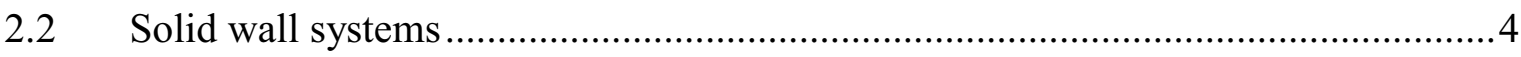

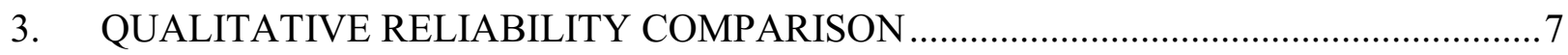

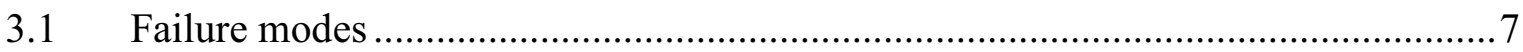

3.2 RAMI Advantages and Disadvantages of Solid Walls ..........................................17

3.3 RAMI Advantages and Disadvantages of Liquid Walls .......................................22

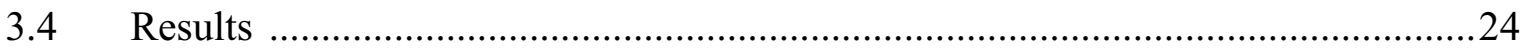

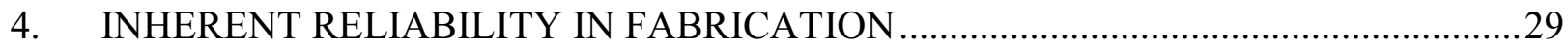

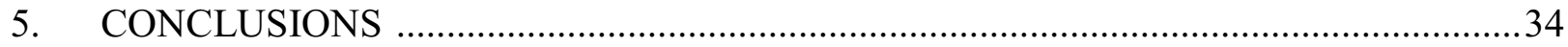

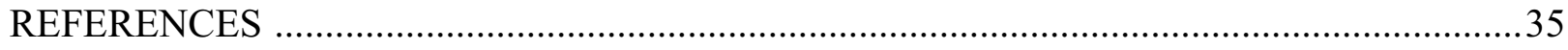

APPENDIX A. Qualitative Reliability in Design .................................................................

\section{TABLES}

S-1. Comparison of Reliability Features of Interest ……………………………………...

1. Characteristics of CLiFF and GMD Design Approaches ................................................

2. $\quad$ Engineering reliability issues with solid wall and liquid wall designs ............................8

3. Solid and Liquid Wall Conceptual System Reliability Comparisons ..............................18

4. Qualitative reliability ranking factors for Solid and Liquid walls .................................19

5. Typical manufacturing techniques for cooling loop components ...................................30 


\section{ACRONYMS}

ALPS Advanced Limiter-divertor Plasma-facing Systems

APEX Advanced Power Extraction study

ARIES Advanced Reactor Innovation and Evaluation Study

ASME American Society of Mechanical Engineers

CLiFF Convective Liquid Flow First Wall

DOE Department of Energy

Flibe $\quad$ Fluorine-Lithium-Beryllium molten salt

FMEA Failure Modes and Effects Analysis

FMIT Fusion Materials Irradiation Test

FW/B first wall/blanket

GMD Gravity and Momentum Driven

HIP hot isostatic press

ITER International Thermonuclear Experimental Reactor

JET Joint European Torus

LOCA Loss of coolant accident

LOFA Loss of flow accident

LOVA Loss of vacuum accident

MHD Magnetohydrodynamic

MTBF Mean time between failures

MTTR Mean time to repair

PFC Plasma facing component

RAMI reliability, availability, maintainability and inspectability 


\section{QUALITATIVE RELIABILITY ISSUES FOR SOLID AND LIQUID WALL FUSION DESIGNS}

\section{INTRODUCTION}

Some members of the magnetic fusion community have suggested that conventional solid walled plasma facing components for magnetic fusion are not reliable enough to make the overall fusion plant economically attractive, and they have suggested design alternatives such as liquid self-renewing walls. Other members of the magnetic fusion community believe that strides have been made in solid walls and are dubious of the technical feasibility of liquid walls. This report is an initial study of qualitative reliability aspects for solid wall plasma facing component (PFC) and liquid metal wall protection schemes for magnetic fusion reactor vessel protection and heat removal. Component reliability is traditionally thought of as a statistical discipline using quantitative values; however, there are important qualitative aspects of reliability as well. Qualitative reliability is examining the system or component failure modes (the manner in which systems or components can fail) and determining the effects of these failures. Qualitative reliability can also include the choice of a design practice that will enhance field performance of a product. An illustrative example of design choices for magnets is given here. Resistive magnet designs use epoxy as an electrical insulation material. Magnet fabricators have learned that the epoxy is best applied by vacuum impregnation into the wound coil. Initially, pressurized epoxy impregnation was used but this was found to leave gas pocket voids in the epoxy. The preference for vacuum impregnation has been recognized for some time, and is adopted in all recent magnet designs (Citrolo, 1993; Thome, 1998). Vacuum impregnation will enhance the field performance and increase the quantitative reliability of each magnet that is constructed.

The qualitative reliability concept is described further in this report, including Appendix A. The appendix also holds a discussion where criteria to judge the quantitative reliability of a design are identified, described, and used to compare the basic solid and liquid wall design approaches. The two basic in-vessel system approaches are briefly explained and then compared. Some reliability issues in component design and fabrication are discussed. Advances in fabrication to enhance reliability are also discussed. Then comparisons are made using a failure modes and effects analysis (FMEA) based approach and criteria assessment. Conclusions are given at the end of the body of the report. 


\section{OVERVIEW OF LIQUID AND SOLID WALL CONCEPTUAL DESIGNS}

This section gives general descriptions of the two types of systems. These descriptions are not detailed because the level of detail varies with these two types of systems. While there have been many solid wall designs, in varying levels of detail, only the design concept is needed for this comparison. Conversely, the liquid wall design is in its early conceptual design phase and does not have a detailed final design at this time. Fusion researchers are working to increase the design details of liquid wall systems.

\section{$2.1 \quad$ Liquid wall systems}

The liquid wall concept is a flowing liquid metal (lithium or lithium-tin alloy [Sze, 1999]; possibly the molten salt Flibe) flowing in a thick layer $(\sim 1 \mathrm{~m})$ from nozzles at the top of the vessel down the walls to a collection nozzle at the bottom of the machine. There the coolant can be pumped out to a heat removal component, the impurities removed, and then the coolant is re-introduced at the top of the vessel. Current reasons for exploring the liquid wall concept have been discussed by Abdou (2000), Moir (1995), and Morley (1995). Abdou has suggested that the liquid wall concept will accommodate high power densities where surface heat fluxes are over $2 \mathrm{MW} / \mathrm{m}^{2}$, and these systems could also have a high power conversion efficiency of over $40 \%$. Abdou also asserts that the design should have a high availability for an economically attractive power plant. Abdou has also pointed out that the liquid wall, being an electrically conducting shell, will improve plasma stability and plasma confinement. The liquid wall is also stated to offer increased disruption survivability, somewhat reduced waste volume, and faster maintenance. Moir stated that the self-renewing thick liquid layer $(0.5 \mathrm{~m}$ of Flibe or $1.6 \mathrm{~m}$ of lithium) allows longer irradiation lifetime of the vacuum chamber, less irradiation of the chamber walls to permit shallow land burial, and if fast moving, the liquid can remove a considerable radiative surface heat flux. Calculations by Youssef (2000) also show reduced radiation damage (increased lifetime). Morley has discussed the thin liquid film wall for divertors. The benefits are protection of the underlying surface from erosion and blistering, continual replenishment of the liquid surface, large heat removal capability, and reduced heat penetration to the structure. Morley also added these benefits: elimination of the complications of armor tile attachment, the possible reduction of tritium inventory trapped in immobile armor materials, and the possible elimination of beryllium as a plasma facing material.

There are two basic liquid wall design concepts currently under study by the fusion community. The first of these two basic concepts is a thin (perhaps $2 \mathrm{~cm}$ ), flowing liquid wall as the first wall, then a solid metal wall. Behind the solid metal wall is a thicker liquid layer serving as a blanket. This concept is CLiFF, which stands for Convective Liquid Flow First Wall (Ying, 1999). The idea of the CLiFF design is that the fast moving thin layer of liquid facing the plasma takes the plasma heat at the surface, and the thicker layer of liquid behind is a neutron shield and also heat transfer media. The details of how fast the thick layer is moving and how it is confined are not as evident as for the second design described below. 
The other major concept is referred to as GMD, meaning gravity and momentum driven flow (Ying, 1999). The GMD is a single, thick (perhaps $45 \mathrm{~cm}$ for Flibe, and up to $1 \mathrm{~m}$ for lithium) flowing liquid wall that acts as both a first wall and blanket. Both the CLiFF and GMD concepts use nozzles to introduce the flow through penetrations in the vacuum vessel, and exit nozzles collect the flow for readmission into the piping network. The inlet nozzles may oscillate to vector flow throughout the wall area. The liquid flow rates are high, at 10 to $15 \mathrm{~m} / \mathrm{s}$ to reduce free surface flow "thinning" from gravitational acceleration and toroidal surface area expansion. Ying states that about $30 \%$ thinning can occur at the reactor midplane for a Flibe initial velocity of $15 \mathrm{~m} / \mathrm{s}$ and initial thickness of $50 \mathrm{~cm}$. The flow direction is always top to bottom. Very large volumetric flow rates are needed for ARIES scale power reactors, about $300 \mathrm{~m}^{3} / \mathrm{second}$, with an in-vessel inventory of about $220 \mathrm{~m}^{3}$. Table 1 gives a few of the general design characteristics for CLiFF and GMD approaches.

There are three coolants under consideration for the liquid wall designs. These are liquid lithium, liquid lithium-tin, and the molten salt Flibe. Flibe is under consideration mainly for the confined, thick layer in the CLiFF design. These coolants have the advantages of being able to operate at high temperatures, hence the attractive station efficiency of over $40 \%$ as cited by Abdou (2000), and low pressure (assumed to be less than $0.2 \mathrm{MPa}$ in the piping). The coolants have been chosen for their low vapor pressures, since they would be operating in a vacuum, and for neutron reactions that reduce fluence to the solid walls of the vacuum vessel. The liquid metals will need an electrical insulation layer between the solid metal walls and the flowing liquid metal to reduce magneto-hydrodynamic (MHD) drag (Ying, 1999). Insulation materials such as AIN and $\mathrm{CaO}$ have been under investigation as insulation coatings that are compatible with lithium (Natesan, 1995). These types of insulation coatings are assumed to be under consideration for use in the CLiFF and GMD designs.

From a chemical reactions standpoint, the Flibe appears to be the most benign of the choices. Molten lithium is known to react vigorously in air, and lithium-tin alloys are also pyrophoric (Bretherick's, 1999). The lithium-tin alloy is not as reactive as pure lithium with water (Anderson, 2000).

Table 1. Characteristics of CLiFF and GMD Design Approaches (from Ying, 1999)

\begin{tabular}{|l|c|c|c|c|}
\hline Parameters & \multicolumn{2}{|c|}{ CLiFF } & \multicolumn{2}{c|}{ GMD } \\
\hline Fluid & $\mathrm{Li}$ & Flibe & $\mathrm{Li}$ & Flibe \\
\hline $\begin{array}{l}\text { Operating } \\
\text { temperature, }{ }^{\circ} \mathrm{C}\end{array}$ & 400 & 500 & 500 & 550 \\
\hline Film depth, cm & 2 & 2 & 40 & 45 \\
\hline $\begin{array}{l}\text { Film velocity, } \\
\mathrm{m} / \mathrm{s}\end{array}$ & 10 & 10 & 10 & 8.1 \\
\hline Prandtl number & 0.034 & 33 & 0.0269 & 25.56 \\
\hline $\begin{array}{l}\text { Reynolds } \\
\text { number }\end{array}$ & $2.44 \mathrm{E}+05$ & $2.71 \mathrm{E}+04$ & $6.19 \mathrm{E}+06$ & $6.32 \mathrm{E}+05$ \\
\hline $\begin{array}{l}\text { Hartmann } \\
\text { number }\end{array}$ & $7.13 \mathrm{E}+05$ & $8.13 \mathrm{E}+02$ & $4.29 \mathrm{E}+05$ & 685.14 \\
\hline
\end{tabular}




\subsection{Solid wall systems}

The solid wall PFC armor tile approach has been under consideration, and in use at existing fusion experiments, for many years. In the early 1980's, high atomic weight materials, such as tungsten, were used. This was followed by graphite and carbon fiber composite materials. Then in the 1990's, beryllium was used as a tile material. There have been plans to use plasma sprayed beryllium as a coating over higher atomic weight materials to take advantage of beryllium's lower atomic weight. The fusion program has stopped searching for one material that will meet all first wall and divertor in-vessel needs. Now, mixed materials and layered materials are under consideration for fusion designs such as the Fusion Ignition Research Experiment (FIRE) and the International Thermonuclear Experimental Reactor (ITER).

The basic solid wall PFC configuration considered in this report is cooling channels within a substrate; these channels route cooling fluid near the outer side of PFC armor tiles. The plasma facing side accepts the radiant heat load and the harsh environment of the fusion plasma, including sputtering, erosion, tritium bombardment, tritium and helium uptake, electromagnetic induced forces, disruption forces, thermo-mechanical stresses, etc. The International Thermonuclear Experimental Reactor (ITER) is an example of a near term solid wall design. The ITER walls were cooled by flowing water, and they could reject heat to the vacuum vessel cooling system. The Advanced Reactor Innovation and Evaluation Study - Advanced Tokamak (ARIES-AT) design is an example of a power reactor based first wall concept. In ARIES-AT, the first wall is silicon carbide, cooled by lithium-lead liquid metal coolant. There are many more solid wall designs in the fusion community.

For this comparison, a generalized solid wall system is considered. The walls use modular construction of first wall/blanket segments, with plasma facing components (PFCs) closest to the plasma. The PFCs could be high or low atomic weight, or high atomic weight with a coating of low atomic weight material; this distinction is not important for the level of analysis. The PFCs are bonded to a metal substrate. The metal substrate is cooled with integral cooling channels. The cooling channels are brazed or welded to cooling manifolds. For purposes of comparison, the coolant is assumed to be the same as for the liquid wall system, either a liquid metal or Flibe. Since lithium coolant is under consideration here, the channels cannot be made of copper; stainless steel and vanadium are options for the cooling channel material. The cooling manifolds enter and exit through penetrations in the vacuum vessel walls. Throughout the cooling channel area is blanket material that interacts with neutrons to reduce fluence to the vacuum vessel and, for the reactor case, to breed tritium. The first wall/blanket (FW/B) segments are mounted to the vacuum vessel wall mechanically in such a way that remote handling is accommodated. The wall modules protect the vacuum vessel. Considering the coolant inventory, some guidance from ITER has been surveyed. The ITER inboard $\mathrm{FW} / \mathrm{B}$ had an in-vessel water coolant inventory of $130 \mathrm{~m}^{3}$, and the outboard FW/B had an in-vessel water coolant inventory of $52 \mathrm{~m}^{3}$. The ITER divertor had an in-vessel water coolant inventory of $48 \mathrm{~m}^{3}$ (SADL2, 1997). Water flow velocities were typically about 5 
$\mathrm{m} / \mathrm{s}$. Considering that the cooling tube diameter and lengths would probably not change appreciably in a conversion to lithium coolant, then a liquid metal cooled, solid wall design would have similar in-vessel coolant volumes to those suggested for the liquid wall design. Flow speeds would likely be smaller for the solid wall system, perhaps on the order of $5 \mathrm{~m} / \mathrm{s}$, to limit the MHD pressure drop. Flow pressures would be higher than the liquid wall systems (but still low relative to water) because the solid wall systems must account for pressure drops in headers and the small diameter tubes. The liquid wall system does not have all of those flow friction losses.

Solid wall designs offer their own advantages. An important fact to realize is that solid walls have improved their robustness and longevity over the last three decades of fusion research; they are more erosion-resistant and can now tolerate high heat fluxes up to and beyond $5 \mathrm{MW} / \mathrm{m}^{2}$ in normal operation and up to $20 \mathrm{MW} / \mathrm{m}^{2}$ in transient conditions. Neutron irradiated carbon fiber composite monoblocks have shown good integrity under electron beam irradiation testing up to $25 \mathrm{MW} / \mathrm{m}^{2}$ (Rödig, 1998). Solid wall designs using high temperature coolants also achieve high power conversion efficiencies (Sze, 1998). Solid wall designs have matured to become more robust against the forces encountered in service, including vibration, electromagnetic-induced forces, thermal stresses, and other plasma-induced forces from normal operation and, more importantly, disruptions. In past decades, solid walls were believed to need frequent changeouts due to wall surface erosion and neutron irradiation, but low activation materials and PFC surface refurbishment via chemical vapor or plasma spray deposition allow longer residence times. The ITER design called for divertor replacement every 3.3 calendar years in the basic performance phase, and first wall module maintenance would be infrequent; that is, less frequent than the divertor (DDR, 1997). Future plant designs, such as the Advanced Reactor Innovations and Evaluation Study (ARIES) suggest even fewer outages for module replacement (Waganer, 2000).

Changeout of the solid wall components do create a low level radioactive waste stream, but the volumes are continually being reduced as research shows that the metallic wall materials can be reused (Cerdan, 1998) or recycled rather than buried. Early design ideas in the ITER project called for changing out wedge sections of the wall; now for ARIES smaller modules are envisioned as being replaced. The solid wall modules require remote handling for their replacement, and the state-of-the-art in remote handling technology has grown in the past three decades to meet such challenges as moving 4 ton modules (see Tada, 1998). The Joint European Torus (JET) had a complete divertor replacement in 1998. It was very successful, showing how remote handling equipment can meet maintenance needs (Cusak, 1998). The ARIES designs call for less downtime than JET required. 


\section{QUALITATIVE RELIABILITY COMPARISON}

This section gives the results of a comparison of the representative designs of solid wall and liquid wall systems described previously. The GMD design has been selected as the liquid wall candidate because it offers the greatest potential for magnetic fusion and is the simplest design offered using the liquid approach. Engineering feasibility (see Liao, 1992) has been assumed for each system design, including braze joints in the solid wall design and the ability to control the free surface in the liquid wall design.

For qualitative reliability, the focus is on the component failure modes and the consequences of those failures rather than the failure rates. The failure modes are the ways in which a component could fail to operate as needed in the design. A failure modes and effects analysis (FMEA) style of analysis (Cadwallader, 1987; Pinna, 1998) has been carried out for the major system components of each design approach.

\subsection{Failure Modes}

The failure modes for major system components have been identified using an FMEAbased approach. These qualitative failure modes are given in Appendix A, with the results for the two system designs compared in a columnar format. Table 2 presents insights gained during the failure mode analysis of the major components in these systems.

The failure mode discussion in Table 2 shows interesting comparisons between the two systems. The first contrast of interest is that while the ex-vessel portions of the systems would appear to be the same, especially with the assumption of the same coolant choice, similar system coolant inventories, and reasonably similar flow rates, there are different dependencies between the solid wall and liquid wall flow systems. In the solid wall system, it is possible that in-vessel flow disturbances that alter the heat removal capability of the system can be accommodated by timely plasma shutdown. Some solid wall designs with low activation materials do not have enough neutron activation decay products to require a decay heat removal system. If they do require decay heat removal, then natural circulation flow is typically designed in to remove the decay heat. If the plasma shutdown system were reliable then the main coolant pumps would not require backups, 'pony' motors, or other special provisions.

By comparison, the liquid wall system critically depends on maintaining flow, as cited by Moir (1995). If flow is lost, wall protection is lost. The substrate wall or the vacuum vessel wall could receive damage unless the plasma is shut down quickly and without 
Table 2. Engineering reliability issues with solid wall and liquid wall designs

\begin{tabular}{|c|c|}
\hline Solid Walls & Liquid Walls \\
\hline $\begin{array}{l}\text { In-vessel components } \\
\text { Piping confinement means that any material- } \\
\text { compatible coolant can be used, such as organics, } \\
\text { water, liquid metal, molten salt, gases, or liquid } \\
\text { chemical solutions. Even steam or tiny solid } \\
\text { spheres might be used as heat transfer media. Wide } \\
\text { ranges of coolant temperature, pressure, and flow } \\
\text { rate are possible. Versatile coolant choices. The in- } \\
\text { vessel piping component count can be quite large, } \\
\text { and the designs complex. In-vessel leaks must be } \\
\text { considered to be anticipated events. Repair may be } \\
\text { difficult, so replacement must be considered as an } \\
\text { important means of repairing in-vessel first wall, } \\
\text { blanket, and/or divertor modules. In-vessel leaks } \\
\text { can lead to plasma disruptions and vice versa. }\end{array}$ & $\begin{array}{l}\text { In-vessel components } \\
\text { Using a free surface in a vacuum limits the coolant } \\
\text { choices. Organics cannot be used due to their high } \\
\text { vapor pressure; water cannot be used since it would } \\
\text { change phase. Gases cannot be used. The tiny solid } \\
\text { spheres may not flow well. Only liquids with low } \\
\text { vapor pressure at vacuum are deemed acceptable for } \\
\text { this application. Temperatures and flow rates can } \\
\text { be high for some coolants, such as liquid metals, but } \\
\text { pressure will be modest. Specific coolant choices. } \\
\text { In-vessel components are few and simple. In-vessel } \\
\text { leaks are not an issue, but dripping or misaligned } \\
\text { nozzles might lead to plasma disruptions. In-vessel } \\
\text { liquid ripple may be suppressed by magnetic fields. } \\
\text { If liquid splashed, there is the possibility of liquid- } \\
\text { plasma interactions. }\end{array}$ \\
\hline $\begin{array}{l}\text { Vacuum vessel } \\
\text { In a loss of vacuum boundary, another breach must } \\
\text { occur to mingle coolant with air. In a LOVA, air } \\
\text { could react with hot tiles. } \\
\text { Some enclosed coolants at high temperature and } \\
\text { pressure could require a suppression tank plumbed } \\
\text { to the vacuum vessel in case of in-vessel breach. } \\
\text { The tank would reduce overpressure. }\end{array}$ & $\begin{array}{l}\text { Vacuum vessel } \\
\text { In a loss of vacuum boundary, the free surface } \\
\text { coolant at high temperature is directly exposed to } \\
\text { air. } \\
\text { The system operates at low pressure and no special } \\
\text { provision for pressure suppression is needed if no } \\
\text { other condensible coolants (e.g., water for plasma } \\
\text { heating antenna arrays, etc.) could leak into the } \\
\text { vessel. }\end{array}$ \\
\hline $\begin{array}{l}\text { Pump reliability } \\
\text { If a pump were to fail, there is the possibility of } \\
\text { coolant overheat and overpressurization leading to } \\
\text { in-vessel pipe failure (depending on the coolant in } \\
\text { use). A design to enhance natural circulation can } \\
\text { provide for natural buoyant circulation flow in case } \\
\text { of a pump outage. If the plasma is shut down in a } \\
\text { timely manner, properly designed natural circulation } \\
\text { flow can adequately remove decay heat. Pumps of } \\
\text { average reliability can be tolerated if the plasma } \\
\text { monitoring sensors and the plasma shutdown system } \\
\text { both have very high reliability. }\end{array}$ & $\begin{array}{l}\text { Pump reliability } \\
\text { The free surface system depends on the "sheet" of } \\
\text { coolant to protect the substrate metal. The metal } \\
\text { may have added thickness for robustness, but liquid } \\
\text { flow is vital to protect the machine. Pumps of high } \\
\text { reliability in redundant and/or diverse (i.e., } \\
\text { electromagnetic and centrifugal) configurations are } \\
\text { needed to provide flow in case a pump is lost, or } \\
\text { emergency pumps are needed. These extra pump } \\
\text { units ensure that the liquid wall continues to flow } \\
\text { for decay heat removal after the plasma is shut } \\
\text { down. Free surface flow from the top to the bottom } \\
\text { of the vacuum vessel will not provide natural } \\
\text { buoyant circulation flow. }\end{array}$ \\
\hline
\end{tabular}


Table 2. Continued

\begin{tabular}{|c|c|}
\hline Solid Walls & Liquid Walls \\
\hline Heat exchanger & Heat exchangers \\
\hline $\begin{array}{l}\text { An important reliability issue with heat exchangers } \\
\text { is leakage from the primary coolant to the secondary } \\
\text { coolant. Generally, solid wall designs have the } \\
\text { primary coolant at higher pressure than the } \\
\text { secondary coolant, so leakage is away from the } \\
\text { tokamak. This is an issue for environmental release } \\
\text { of radioactivity. }\end{array}$ & $\begin{array}{l}\text { Heat exchangers must also be designed with } \\
\text { secondary fluid at a lower pressure, so any internal } \\
\text { leakage would be into the secondary coolant. } \\
\text { Otherwise, a low vapor pressure fluid might leak } \\
\text { into the primary coolant; flow through the core } \\
\text { would allow liberation into vacuum. A design } \\
\text { possibility is using an intermediate heat exchange } \\
\text { loop. An intermediate loop adds to the cost, } \\
\text { maintenance downtime, and reduces the efficiency } \\
\text { of the heat transfer system. }\end{array}$ \\
\hline $\begin{array}{l}\mathrm{C} \\
\mathrm{he}\end{array}$ & $\begin{array}{l}\text { ant, and that is added } \\
\text { ion issue of foreign }\end{array}$ \\
\hline $\begin{array}{l}\text { Ex-vessel piping } \\
\text { The coolants could be high temperature, moderate } \\
\text { pressure, and high flow rate. The piping must be } \\
\text { thick-walled to provide adequate confinement. } \\
\text { Thick walled pipe is costly to purchase, install and } \\
\text { inspect. If a liquid metal coolant is used, some form } \\
\text { of pipe coating insulation would be needed to } \\
\text { electrically isolate the coolant. The electrical } \\
\text { insulator coating might be needed for Flibe as well. } \\
\text { The issues of coating reliability and coating } \\
\text { degradation effects on the flow must be included in } \\
\text { the design. }\end{array}$ & $\begin{array}{l}\text { The coolants are anticipated to be high temperature } \\
\text { and modest pressure, with high flow rates. If a } \\
\text { liquid metal coolant is used, some form of pipe } \\
\text { coating insulation (such as AlN, } \mathrm{CaO} \text {, etc.) would } \\
\text { be needed to electrically isolate the coolant. The } \\
\text { electrical insulator coating might be needed for } \\
\text { Flibe as well. The issues of coating reliability are } \\
\text { then included in the design. A failed coating would } \\
\text { cause MHD drag forces on the coolant, and could be } \\
\text { a contaminant in the liquid wall coolant. A screen } \\
\text { on the flow collection area may not be needed for } \\
\text { all kinds of pumps. }\end{array}$ \\
\hline $\begin{array}{l}\text { Piping failure would require design provisions, such } \\
\text { as a robust confinement barrier to handle } \\
\text { overpressures, or liquid metal safety provisions } \\
\text { described at the right. }\end{array}$ & $\begin{array}{l}\text { ons such } \\
\text { concrete, } \\
\text { or faster } \\
\text { c. }\end{array}$ \\
\hline
\end{tabular}

runaway electron formation. Perhaps the liquid wall system would use low afterheat materials so that decay heat removal is not a concern. Nonetheless, some special provision for maintaining flow is needed for the liquid wall system. An obvious choice is redundant pumps, plumbed in parallel flow paths. The pumps would require independent power and controls. Adding redundant equipment increases the inspection and maintenance time burden of the system, but that provision or some other provision to ensure liquid flow is necessary. As a first approximation, the upper bound reliability of the liquid wall system will be dominated by the 'failure to run' failure rate of one main pump unit. Most of the other components in the system are passive. The passive component failure rates are typically an order of magnitude or more lower than the rates for active components, hence the overall system reliability will be dominated by the reliability of the pump. One pump is chosen since a partial loss of flow will be detrimental to some portion of the substrate wall. 
Other ex-vessel equipment does not appear to be as sensitive to closed or free surface flow design. One issue regarding ex-vessel equipment for both designs is coolant purification. Liquid metal fission reactors (the Experimental Breeder Reactor II (Holmes, 1977), the Fast Flux Test Facility (McCown, 1980), Hallam and Fermi I (Yevick, 1966), Rapsodie, Phenix, and Super-Phenix plants (Abramson, 1976)) have used cold traps to remove oxide impurities. Recent studies of a liquid lithium system also adopted a cold trap for impurity removal (Sze, 1995; Kato, 1998). Both solid and liquid wall approaches are expected to experience some small level of flow-induced erosion (flow speeds can be high but turbulence should be low, so erosion should be low), radiolytic effects, some level of corrosion, and initial and/or periodic impurities (oxides, etc.) that will collectively require some form of purification system. Since lithium will be used (either as lithium, lithium-tin alloy, or in Flibe molten salt), some form of tritium removal will be needed to collect and purify the tritium for use in the reactor. Any degradations in the efficiency of that purification system will have a direct effect on in-vessel system availability, since both systems have concerns to keep heat transfer surfaces clean when operating at high temperatures. Small pipe diameters are known to be susceptible to plugging (generally less than $20 \mathrm{~cm}$ diameter, more prevalent with small diameters such as $2.5 \mathrm{~cm}$ ). The solid wall system has cooling tubes; there is the chance of tube plugging if impurities are allowed to accumulate in the flow loop. Liquid wall nozzles would probably be large diameter (and high flow velocity) and are not likely to be susceptible to plugging.

The liquid wall system must deal with the possibility of a vacuum distillation effect where impurities could leave the coolant under high vacuum and would be poisons to the plasma. Vacuum distillation has been used to purify laboratory quantities of liquid sodium, and has been used on the Russian BR-5 liquid metal fission reactor as a coolant purification system (Yevick, 1966). Olson (1971) described a vacuum distillation system used on the Experimental Breeder Reactor II to sample impurities from small batches of sodium coolant from the secondary coolant loop. This unit operated at a medium vacuum of $0.5 \mathrm{~Pa}$ and the sodium was heated to about $370^{\circ} \mathrm{C}$; effluents were frozen in a freeze trap. The Advanced Power Extraction Study (APEX) is studying the effect of the bulk coolant on the plasma, but they have not yet examined impurity effects (see Rognlien, 2000).

The solid and liquid wall designs differ significantly with regard to the consequences of air ingress into the plasma chamber. The vacuum vessel piping penetrations may be contained in a cryostat under vacuum or within some other barrier. If the penetrations see air, then any fault would leak air into the vacuum vessel. Even if the penetrations are all kept under vacuum, there is the concern that a port failure could allow air ingress into the vacuum vessel. In a solid wall design, air inleakage with hot PFC tile walls would result in chemical reactions with the hot materials (Be, $\mathrm{C}, \mathrm{W}$, etc.), which lead to possible releases of chemically hazardous and radioactive aerosols. However, the degree of the reaction can be quite limited if the hot materials can be cooled quickly (McCarthy, 1996). In the liquid wall design, there is a large surface area of liquid metal or salt that could contact air. Fortunately, Flibe is not noted to react in air, but the liquid metal coolants will react. If there is a large drain tank or tanks provided in the liquid wall design to 
allow faster maintenance on the system, it could be employed to drain the liquid coolant so that reactions in air would be reduced in scale. The liquid metal-air reaction would be quite high temperature, and the heat could damage the substrate coatings, piping, etc., unless the coolant is quickly drained to the holding tank. Following such an event, PFC chemical reactions would require downtime for solid walled-machine cleanup to reestablish good vacuum and tile replacement or surface recoating to renew the PFC armor. The liquid walled-machine is envisioned to only require extensive coolant purification and some small amount of coolant replenishment, and verification that the piping and wall coatings are undamaged. Both systems would require vacuum system cleanup.

The in-vessel components in the two approaches have different failure modes. In the solid wall design, all in-vessel components are passive. While passive components are typically regarded as having good reliability (i.e., small failure rates), there is a real concern that the high population number of these components in the reactor, especially weld joints, will lead to a small number of random faults in each operating campaign. Reviewing operating experience from the fusion experiment Tore Supra at Cadarache, France, which uses actively pumped water coolant for some of its in-vessel protective surfaces, provides some insights. The rationale presented by Tore Supra personnel is that it is an experimental machine; its mission is to "push the limits" of plasma configurations and operating modes. Naturally, the staff avoids repeating any plasma condition or mode that has proven to be harmful to the machine, but as they explore other modes of operation they sometimes find new, previously unrecognized conditions that overstress the machine. A power reactor would not "push the limits", it would operate a steady, optimum controlled plasma, so in-vessel component failure frequencies for a fusion power plant are expected to be much less than those seen at Tore Supra. Experiments that push the limits often result in undesirable plasma situations, such as generating runaway electrons that damage wall materials and creating intense plasma disruptions that stress the in-vessel components; the chamber walls must accept this punishment and continue operating. The current tokamak experiments experience failures whose frequency and severity are not expected in future power plants. Tore Supra has had invessel water leaks, typically fewer than 6/year. Surle (1998) discussed that most Tore Supra leaks have been caused by localized heat flux, faulty design basis, or poor conditioning. The tubing failure modes were typically burnout or joint failure. The staff has learned that water leaks into the vacuum vessel are particularly penalizing to tokamak operation, needing one to four weeks of downtime per leak event to repair the leak and bake out the vessel. Such operating experiences - knowing what situations or practices to avoid so that longevity is promoted - will be very valuable for any future tokamak designs that pursue solid walls. Water leaks are very detrimental to plasma operations, possibly causing disruptions if the leakage flow rates are large (Merrill, 1991). It should also be recognized that a plasma disruption resulting from other reasons may overstress the in-vessel tubing or piping so that a water leak precludes timely plasma restart, putting the reactor into an unscheduled outage.

Another issue with solid wall designs is the planned lifetime of the PFCs. Material erosion is an important concern for solid plasma facing components (Doerner, 1997). 
There is a design balance between the depth of a tile that allows the tile thermal conductivity to adequately transfer heat to the cooling system, and the depth of the tile available for sacrificial erosion. If the tile is too thick, the thermal conductivity of the tile material limits heat transfer and the surface temperatures remain high. If the tile is too thin, then there is not enough erosion margin and the tile will require early changeout. A tile growing too thin has the possibility of detachment (by braze material overheat or thermal overstress of substrate), and detachment could lead to a cascading tile failure (Merola, 1998). Erosion dust also adds to the vacuum vessel's radiological inventory. Some of the early reactor studies planned for routine preventive maintenance replacements of one-fourth of the in-vessel wall modules during an annual, major plant shut down for inspection and maintenance (Baker, 1980). More recent reactor design studies, such as ITER, have estimated that first wall changeouts would be performed on all sectors in one outage, with less frequency (DDR, 1997). ARIES would have less frequent changeouts than the ITER schedule.

The liquid wall system does not have the concerns about outages to repair leaks unless ex-vessel piping or a vacuum vessel wall cracked to allow leakage in an undesirable direction. However, the liquid wall system does have an active in-vessel component, the oscillating flow nozzles. The nozzles are very important equipment items for this system design. If a nozzle were to function incorrectly, the liquid wall may not be properly established. It is possible that a nozzle could erode at its opening, allowing mist or droplet formation, which would be very detrimental to plasma operation, and could lead to plasma disruptions. The nozzle 'mouths' would need periodic inspections and possible replacement (Moir, 1997). If the nozzles were required to oscillate for coverage, then the nozzle oscillation mechanisms would also require periodic inspection and testing, since the interior of a tokamak is known to be a harsh environment for wear (Marmy, 1990). If the nozzle oscillation could be driven by the flow of coolant itself, or perhaps lubricated by the coolant, the reliability would be greater and there would be fewer issues with nozzle lubricant (such as $\mathrm{MnO}_{2}$ ) contamination, no lubricant reservoirs needed, radiolysis or other breakdown of paste lubricants, etc. Another issue for the nozzles is that the nozzle aim must be verified on a periodic basis. The nozzle precision must be as good as the module alignment in solid wall designs, even though the nozzle could be oscillating. If a nozzle were to come out of alignment, the results could be very damaging for the substrate walls, and possibly the vacuum system. If a nozzle comes out of alignment by even a small amount, such as $1^{\circ}$ of its arc travel, it is likely to lead to non-uniform thickness of flow the midplane of the machine. Non-uniformity would lead to substrate plate heating.

There does not appear to be a surface erosion problem with the liquid wall system since the liquid flow is self-renewing; any sputter from the liquid surface should be drawn back to the flowing liquid by the magnetic fields. However, the interaction between the liquid wall surface and the plasma is not fully understood. Detrimental plasma/liquid interactions with a liquid wall system are considered to be more likely than with solid wall systems. 
A screen was assumed in the collection nozzles of the liquid wall design, since it is good engineering practice to use a screen whenever a liquid is being collected and routed into piping systems. Stopping debris at a screen would save the pump from impeller damage, but could create loss of flow situations. However, it is not immediately evident that there can be any debris accumulating in this design. Plasma diagnostics have moved away from retractable probes in favor of less obtrusive methods, but there still exists a chance that some metal object (weld slag, a piece of a valve seat or heating antenna, etc.) could move through the system. The liquid wall design may or may not use flow diversion vanes. If so, a piece of a flow vane could add to the list of debris. Fission reactors have had a variety of foreign objects inadvertently introduced into the cooling systems, including a workman's glove, paint brush, wooden block, scraps of metal debris from construction, etc. The screen acts to protect the downstream piping and the pump units. It is possible that a screen could be placed outside the tokamak but still ahead of the pump inlets. It is also possible that some type of loose parts monitor (typically an acoustic monitor for present day power plants) could be used to advantage instead of relying on a screen.

The cleanliness of the vacuum system can have an impact on overall system availability. Good vacuum conditions must exist to operate the plasma. Typically, the solid wall system strives for low atomic weight PFC materials to reduce the plasma heat loss effects of any wall particles intruding into the plasma. The particles can be sputtered, volatilized or otherwise liberated from the solid wall surface and migrate to the edge plasma region. Vacuum pumping will not remove all of these particles. There is a similar, but possibly more important, issue to consider with liquid walls. There can be sputtering, but also liquid vaporization. Kolowith (1985) discussed detailed experiences of operating a liquid lithium loop at $270^{\circ} \mathrm{C}$ in a vacuum of $0.1 \mathrm{~Pa}$ to $1 \mathrm{E}-04 \mathrm{~Pa}$. This loop operated as part of the Fusion Materials Irradiation Test (FMIT) program at Hanford, to develop components and operating procedures for the FMIT lithium system. The "vacuum operation was plagued by vacuum gauge failures and increasing vacuum and safety relief valve seat leakage. These problems have been attributed to lithium vapor/aerosol transport throughout the vacuum system." (from Kolowith, 1985, page 125) The major components of the white film 'lithium frost' were $67 \%$ lithium, $25 \%$ sodium from the sodium impurity in the lithium, and $8 \%$ potassium from the potassium impurity in the lithium. Kolowith noted that the delivered lithium underwent a compositional analysis and it was found to exceed the stated levels of sodium and potassium impurities, which helps explain the percentages of the frost composition. The rate of frost formation on the walls of the system after 8 hours of vacuum operation was estimated to be $0.17 \mathrm{mg} / \mathrm{cm}^{2} /$ day. These films were not the result of direct splashing deposits, but of lithium aerosol in the vacuum system. The aerosol moved about the vacuum system without difficulty. A foreline trap was suggested ahead of the roots blower, although the blower did not exhibit any degradation from lithium frost found inside the unit. No mention was made of the cryopump performance with lithium frost; the vacuum system may not have operated very long at low pressures for the free surface lithium runs.

Another vacuum system cleanliness issue is helium ash pumping. Cryogenic pumps are often favored since these pumps are passive units with no concerns about magnetic fields, 
they are very clean and offer high vacuum capability. Unfortunately, cryopumps typically have a low adsorption capacity for helium compared to other gases. Consequently, the helium ashes from fusion reactions are not easily pumped into the vacuum system ports. In solid wall experiment designs, the helium ash is basically entrained by unburned deuterium and tritium that is flowing into the vacuum ducts. The deuterium and tritium help to cryotrap the helium (O'Hanlon, 1989). In the liquid wall system, these hydrogen isotopes have solubility in lithium (Katsuta, 1977). The lithium can accept some of the deuterium and tritium into solution, so that it does not travel to the vacuum system. A comparison of the solid wall material tritium uptake versus liquid wall tritium uptake must be performed to determine the extent of this effect. There could be less entrainment of helium into the vacuum system of a liquid wall design. If cryopumps are not feasible, then some other vacuum pump would be needed, and would have to be evaluated for compatibility with the liquid wall coolant, ability to pump helium, etc.

Another impurity issue is that if the cooling system must be opened for any reason (valve seat inspection or repair, component replacement, etc.), the frozen 'lithium plug' surfaces will be exposed to impurities in air or in any cover gas used. For solid wall systems, such impurities would be removed in the purification system. For liquid wall systems, the impurities would also be removed by the purification system, but they might also be liberated from the free surface under vacuum in the vacuum distillation type of process mentioned earlier in this section. Therefore, a pre-operational time period of operating the liquid wall system at temperature and under high vacuum to "purge-condition" the liquid will probably be needed whenever the system has been opened for invasive maintenance or inspection. As a first intuition, this time may be shorter duration than, but similar in necessity to, solid wall "bake-out conditioning" that removes water vapor from the solid walls. This conditioning time requirement adds to the outage duration.

An important issue for minimizing downtime is the ability to heat the system piping in either system. The coolant may be stored at temperature in a holding tank, but the piping must have the ability to be heated so that when the coolant is sump pumped back into the flow loop it does not cool and solidify. Some means of heating the piping, such as electrical heat tracing, and vessel heating, similar to the bakeout system used for solid wall tokamaks, is needed for both the solid and liquid wall systems. Otherwise, there is a risk of coolant cooldown and freeze plugging in the system. Therefore, the liquid wall system does not preclude the need for a vessel warming subsystem. If the vacuum vessel itself has a cooling system (such as a jacket cooling system, or a flow space between double walls, etc.), then that system could be operated with a hot gas to pre-heat the vacuum vessel, then drained and filled with the coolant of choice for plant operation. A good choice for liquid metal walls would be to use helium coolant in the vacuum vessel jacket or annulus. With either design approach, plant startup will take some amount of time; it will probably not be a short 30 or 60 minute ramp up to power operation.

Both systems would be subject to required outages for piping inspection. Section XI of the ASME Boiler and Pressure Vessel Code gives direction for a 10-year in-service inspection. The ASME B31.1 (Power Piping) code also directs periodic inspections. 
While fusion may or may not need to comply with these codes, severe piping failures at US fossil-fueled steam electric power plants (Bangs, 1986) illustrate that it is prudent to inspect high-pressure, high-temperature piping at some periodic frequency. Typically, power plant personnel and radiography subcontractors will perform this inspection in segments or sectors during yearly outages so that over 10 years the required component inspections are completed. Then the next year inspections begin again to complete another cycle within 10 more years. Such a cycle allows the plant downtime to be minimized and costs to be leveled on a yearly basis. Components are tracked so that the ten-year interval is observed. For tokamak in-vessel components, the solid wall system inspections will require a large effort until operation shows the most sensitive areas to inspect and suggests reasonable time intervals between inspections. A demonstration reactor may provide insights to streamlining the inspection process. Liquid wall systems would also require inspections of the substrate plates for cracking, insulation coating for integrity, the flow vanes (if used) for cracking, the flow nozzles for erosion, and collection nozzles for erosion. These inspections will be less time duration than the solid wall inspections, but they are necessary and will add some downtime to the liquid wall design.

Another periodic inspection issue is flow instrument (pressure, temperature, flow rate, etc.) calibration. These instruments are required to be operable for plant operation. Such instruments are often doubled and tripled for redundancy to preclude unnecessary plant downtime, but the instruments still require periodic calibration. Since liquid metal and molten salt systems operate at high temperatures, these systems will need to be cooled down for personnel to approach the instruments to perform component inspections and instrument calibrations. The system cooldown and subsequent heatup will add additional time to outages when compared to water coolant systems. One method to reduce the heatup/cooldown time issue for both the solid and liquid wall systems would be a coolant holding tank and inert gas fill system. Then the coolant could be drained while at temperature to the holding tank via piping 'low point' drains. As the coolant drains, the piping could be filled with an inert gas to avoid creating vacuum as the liquid drains. The inert gas also minimizes coolant contamination. Recalling that the piping could operate as high as $550^{\circ} \mathrm{C}$, and is insulated and perhaps double walled (Yevick, 1966), the piping cool down time must be accounted for so that the surrounding air temperatures are below $54^{\circ} \mathrm{C}$ (Bongarra, 1985) for worker residence near the piping. The piping must cool enough so that heat transfer to room air is below discomfort levels of heat flux for humans. The cool down may take some time since the piping will likely be insulated to retain coolant heat during operation. A tolerance limit for skin exposure to heat is suggested to be $0.25 \mathrm{Watt} / \mathrm{cm}^{2}$ (Cote, 1992). Generally, prolonged hand contact to metal surfaces requires contact temperatures below $40^{\circ} \mathrm{C}$.

Appendix A of this report presents design reliability ideas, and explains the origin of several key features to address for in-vessel system reliability. These features are fault tolerance, surface damage tolerance, durability, and maintainability. Table 3 gives comparisons of these features for solid and liquid wall design concepts. 
Table 4 gives ranking factors based on a set of general qualitative reliability criteria known to enhance the field reliability in many industries. These criteria are described in Appendix A. This ranking has been performed to indicate the relative strengths and weaknesses of the two design approaches. The ranking is subjective; brief reasons for the ranking are given in the table. A value of 0 is a low score, and a value of 3 is the highest score possible. The two designs compare closely, showing that the strengths and weaknesses tend to offset each other.

\subsection{RAMI Advantages and Disadvantages of Solid Walls}

From a reliability, availability, maintainability and inspectability (RAMI) perspective, solid walls have positive and negative features. Some of these features were delineated in Table 3. A more detailed discussion is given here.

There are several advantages of solid walls. A fundamental advantage is that many coolants might be used for solid walls, such as helium gas, water, liquid metal, or organic coolants. Therefore, the safest coolant can be selected since there is no vapor pressure concern. Piping and other coolant system materials can be chosen for material compatibility with the preferred coolant. Another important advantage is that the technology is proven. Solid walls are feasible, and have operated in a variety of tokamaks that have studied various individual aspects of plasmas (high beta, long pulse, high fusion power, deuterium-tritium burn, etc.). The operating environment challenges of high heat flux, erosion, neutron and other radiation damage, thermal stress, mechanical stress, and vibration have been studied and many advances have been made. Many fusion programs around the world are making efforts to create a solid wall that can function well in a fusion environment. Monoblocks with enhanced heat transfer to the coolant have been developed. Many fusion programs are also using electron beam high heat flux tests on prototypic designs of first walls and divertors. The decade-old fault events where wall tile mock-ups failed before the testing was completed (such as described in Croessmann, 1988) no longer exist. Solid walls, especially those in the most 
Table 3. Solid and Liquid Wall Conceptual System Reliability Comparisons

\begin{tabular}{|c|c|c|}
\hline $\begin{array}{l}\text { Feature of } \\
\text { interest }\end{array}$ & Solid wall design concept & Liquid wall design concept \\
\hline $\begin{array}{l}\text { Fault } \\
\text { tolerance }\end{array}$ & $\begin{array}{l}\text { In the ITER design, the in-vessel PFC } \\
\text { cooling could be lost without an accident } \\
\text { event if the plasma were shut down } \\
\text { promptly. In ITER, natural circulation } \\
\text { cooling was available to remove decay heat } \\
\text { from the PFCs. Wall thermal or } \\
\text { mechanical damage could be tolerated } \\
\text { unless coolant was lost into the vessel. In } \\
\text { ARIES-AT (Petti, 2000), the decay heat is } \\
\text { low enough that natural circulation is not } \\
\text { necessary to stabilize the plant after a loss } \\
\text { of cooling. }\end{array}$ & $\begin{array}{l}\text { A loss of pumping may not be tolerable to } \\
\text { the substrate wall. The substrate wall and } \\
\text { its MHD coating would have to be robust } \\
\text { for possible exposure to increased heat flux. } \\
\text { Nozzle malfunction would not be tolerable. } \\
\text { Nozzle malfunction could lead to wall } \\
\text { overheating or to plasma disruption. Flow } \\
\text { disturbances (ripples) could lead to } \\
\text { localized wall overheating. It is not clear at } \\
\text { this time what sensors would be used to } \\
\text { monitor the operation of the liquid wall. }\end{array}$ \\
\hline $\begin{array}{l}\text { Surface } \\
\text { damage } \\
\text { tolerance }\end{array}$ & $\begin{array}{l}\text { PFC surface erosion is also an important } \\
\text { concern that limits lifetime. It can be } \\
\text { treated by plasma spray or chemical vapor } \\
\text { deposition, but that means additional } \\
\text { downtime for treatment with magnets } \\
\text { deenergized. Erosion is a serious problem } \\
\text { for pipe wall surfaces due to high speed } \\
\text { flow of } 5 \mathrm{~m} / \mathrm{s} \text { or higher and the bends the } \\
\text { flow must negotiate. }\end{array}$ & $\begin{array}{l}\text { The liquid is self-renewing, so there are no } \\
\text { PFC erosion concerns. There is a concern } \\
\text { about lithium frost intruding in other parts } \\
\text { of the system, on instruments and in } \\
\text { vacuum components. There are concerns } \\
\text { that the high velocity flow of } 10 \mathrm{~m} / \mathrm{s} \text { or } \\
\text { more could lead to erosion of flow nozzle } \\
\text { surfaces. }\end{array}$ \\
\hline Durability & $\begin{array}{l}\text { Solid walls have robust designs to handle } \\
\text { off-normal stresses and still be within the } \\
\text { several ton weight limits to be removable } \\
\text { by remote handling equipment. Runaway } \\
\text { electrons and localized hot spots pose a } \\
\text { threat in existing machines. Solid walls } \\
\text { have made significant improvements in } \\
\text { handling heat loads and in longevity. }\end{array}$ & $\begin{array}{l}\text { It is uncertain how the liquid will react to } \\
\text { plasma disruption stresses. Runaway } \\
\text { electrons do not appear to be a serious } \\
\text { concern for liquid wall designs. The "self- } \\
\text { renewing" feature of liquid walls makes } \\
\text { them quite durable. Disruptions could } \\
\text { allow more lithium frost to be liberated into } \\
\text { the vacuum environment, requiring } \\
\text { instrument and vacuum system cleaning } \\
\text { before resuming operations. }\end{array}$ \\
\hline $\begin{array}{l}\text { Maintain- } \\
\text { ability }\end{array}$ & $\begin{array}{l}\text { The solid wall would need periodic } \\
\text { replacement due to wear and activation } \\
\text { considerations. Downtime is not } \\
\text { significant for ARIES (Waganer, 2000). } \\
\text { JET experience with in-vessel divertor } \\
\text { changeout was about } 15 \text { weeks (Mills, } \\
\text { 1999). Between JET and ARIES, the } \\
\text { outage time will be reduced through design } \\
\text { simplification, lessons learned, and more } \\
\text { remote equipment. Equipment has been } \\
\text { developed and tested on present tokamaks. }\end{array}$ & $\begin{array}{l}\text { Liquid walls are "self-renewing." Filtration } \\
\text { of activation products and impurities could } \\
\text { allow very long-lived wall fluid. Nozzles, } \\
\text { vanes, substrate plates, insulation coatings, } \\
\text { and screens (if used) will require periodic } \\
\text { inspection and may need periodic } \\
\text { replacement. The active nozzle component } \\
\text { in a plasma environment is a large concern. } \\
\text { The downtime for replacements may not be } \\
\text { as lengthy as for solid walls because fewer, } \\
\text { lighter components would be handled by } \\
\text { the remote handling equipment. }\end{array}$ \\
\hline
\end{tabular}


Table 4. Qualitative reliability ranking factors for Solid and Liquid walls

\begin{tabular}{|c|c|c|}
\hline Criteria & Solid wall & Liquid wall \\
\hline $\begin{array}{l}\text { Minimum number of parts } \\
\text { in use }\end{array}$ & $\begin{array}{l}1, \\
\text { Use is minimized; numbers } \\
\text { are still very high }\end{array}$ & $\begin{array}{c}3, \\
\text { A good minimization of } \\
\text { parts to use the liquid as a } \\
\text { wall }\end{array}$ \\
\hline $\begin{array}{l}\text { Inherently reliable parts in } \\
\text { use }\end{array}$ & $\begin{array}{c}2, \\
\text { Parts are passively reliable }\end{array}$ & $\begin{array}{c}2, \\
\text { Most parts are passive }\end{array}$ \\
\hline Standardized parts in use & $\begin{array}{c}0, \\
\text { No parts of this nature are } \\
\text { used, all must be fabricated } \\
\text { to specifications }\end{array}$ & $\begin{array}{c}0 \\
\text { The parts must be } \\
\text { specialized for this purpose }\end{array}$ \\
\hline $\begin{array}{l}\text { Operating experience } \\
\text { feedback in use }\end{array}$ & $\begin{array}{c}2, \\
\text { Good use of feedback from } \\
\text { Tore Supra and other } \\
\text { applications }\end{array}$ & $\begin{array}{c}1, \\
\text { Feedback does not appear to } \\
\text { be considered from all } \\
\text { possible applications, such } \\
\text { as Kolowith (1985) and } \\
\text { systems mentioned by } \\
\text { Katsuta (1998) }\end{array}$ \\
\hline Comp & $\begin{array}{c}1, \\
\text { Little de-rating. Typically } \\
\text { this is difficult since mass } \\
\text { must be minimized. }\end{array}$ & $\begin{array}{c}1, \\
\text { Few opportunities to de-rate } \\
\text { components }\end{array}$ \\
\hline $\begin{array}{l}\text { Judicious safety margins in } \\
\text { use }\end{array}$ & $\begin{array}{c}2, \\
\text { These margins are used } \\
\text { when possible for longevity } \\
\text { of the system }\end{array}$ & $\begin{array}{c}2, \\
\text { This system can rely partly } \\
\text { on the high safety margin } \\
\text { vacuum vessel for partial } \\
\text { confinement; penetrations } \\
\text { must also be high safety } \\
\text { margin }\end{array}$ \\
\hline $\begin{array}{l}\text { Subcomponent test program } \\
\text { in use }\end{array}$ & $\begin{array}{c}3, \\
\text { Good use of component } \\
\text { testing programs, } \\
\text { independence and breadth }\end{array}$ & $\begin{array}{c}2, \\
\text { Beginning to use testing in } \\
\text { CDX-U machine, plans to } \\
\text { test in other tokamaks, e.g., } \\
\text { NSTX }\end{array}$ \\
\hline Totals & 11 & 11 \\
\hline
\end{tabular}


severe conditions in the divertor region, can withstand high heat fluxes. Tests by various electron beam facilities (Rödig, 1998; Suzuki, 1994; Castro, 1998) now show tiles that give thousands of cycles at high heat fluxes. Traditional tile walls can now accept high heat fluxes of $25 \mathrm{MW} / \mathrm{m}^{2}$ for thousands of cycles. There are new ideas as well; for example, the tungsten brush design (Smid, 1998), that shows promise for handling high heat fluxes.

Another advantage of solid walls is the advent of new manufacturing techniques that can fabricate the walls with enhanced material properties (Waganer, 1999). The laser forming technique holds promise for any fusion design. It is discussed in the next section.

Disadvantages of solid walls are also numerous. This is because of the harsh working environment that these walls must endure. The prime environmental conditions that the walls must face are:

- $\quad$ Erosion of plasma facing component surfaces

- Runaway electron damage

- $\quad$ Cyclic high heat flux

- Vibration induced by forces and by flow of coolant

- $\quad$ Erosion of pipe walls from fast-flowing coolant

- $\quad$ Electromagnetic forces from the plasma and the magnetic fields

- Thermal stresses

- Neutron and charged particle radiation damage

There is a need to refresh the surface because of erosion from the plasma in present machines, so there is some amount of machine downtime to refresh the walls. Currently, tokamaks are experimenting with use of boron as a wall coating material. The boron is deposited either from diborane gas, which was used at the TFTR, or decaborane gas which is being used at JT-60. A beryllium surface applied by spray has also been investigated (Castro, 1998).

Perhaps less important than the materials issues, but still important for availability, is invessel component survival under disruption stresses. The mounts must resist torque and electromagnetic induced stresses so that the modules can be detached for changeout. In the ITER design, the in-vessel modules transferred the stresses to the wall of the vacuum vessel.

Runaway electrons are a real concern for operating tokamaks. A recent paper from the JT-60 machine (Kishimoto, 1998) gave a photo of runaway electron damage to a cooling pipe. A $4 \mathrm{~mm}$ diameter crater at the outer surface of a divertor coolant pipe led to about a $0.6 \mathrm{~mm}$ diameter penetration of the pipe wall. That thru-wall melt allowed the divertor pipe to leak into the vacuum vessel. Present-day fusion experiments experience runaway electrons periodically; recalling the discussion by Tore Supra personnel, there is an 
expectation that a fusion power plant reactor will not see runaway electrons very often, if at all.

The cooling channels in a solid wall can be complicated because of their number and attachments to headers. The ARIES design has simplified the cooling channel design (Tillack, 2000) so there are fewer channels. Each unit would still require meticulous construction and quality assurance, since the plasma may not be able to tolerate one or more tiny coolant leaks into the vacuum chamber. Such painstaking construction is costly, but manageable for a modest number of modules and cooling channels.

The wall modules would need periodic replacement. While current designs give credit for long-lived first wall modules, there is a concern that the divertor modules would need replacement every few years. Since the neutron activation makes these modules radioactive, they will be replaced using remote equipment. Requiring remote equipment means additional concerns over the reliability of the remote equipment (i.e., need for a remote "rescue" machine in case of equipment failure) and the time duration/speed at which such equipment can accomplish tasks. A landmark event was the JET solid divertor removal and replacement with a gas box divertor. The replacement task required almost 15 weeks (Mills, 1999), using remote equipment for divertor removal and assembly. This time could have been shorter if the replacement divertor was the same design as the removed divertor, and 24-hours per day operation was used to minimize downtime. It is reasonable to assume that lessons learned will lead to shorter down times for future remote handling activities. Examination of nuclear fission plant refueling outages (not the same sort of activity but parallel in scope and complexity) shows that initial refueling outages required longer times than current outages. Typically, task planning improved with practice, staff learned the tasks and performed them faster, fewer plant modifications are needed in current outages than in early ones, and fewer corrective maintenance activities are needed during current outages. For these reasons, it is expected that 15 weeks is a liberal upper bound for a fusion power plant solid divertor replacement outage. Looking to the future, the ARIES design considers 20 days/year of unscheduled shutdown, and can still provide an $88 \%$ plant availability (Waganer, 2000).

As mentioned earlier, inspectability is an important issue. The US Nuclear Regulatory Commission requires inspections of fission power plants. The ASME boiler and pressure vessel code, and the ASME power piping code discussed earlier require fossil-fueled power plants to inspect piping. It is likely that the cooling system of a fusion reactor would have similar requirements.

\subsection{RAMI Advantages and Disadvantages of Liquid Walls}

The primary advantage of liquid walls is that the coolant acts as the wall protective armor. There are no plasma erosion concerns like solid walls face, since the coolant is flowing and replenishing itself. The choice of coolant can have the advantages of efficient heat transfer and good thermal efficiency, low pumping power, resiliency to radiation and thermal damage, low corrosion, and low cost. The free surface cooling adds a constraint that the coolant must have low vapor pressure. 
A distinct reliability advantage for liquid walls is that there are few parts, and the existing parts are simple in design. The liquid wall does not have all of the solid metal material that solid wall designs have; fewer welds and brazes, no mechanical fasteners (i.e., bolts), no modular sections requiring changeout every few years. The liquid wall design has simple in-vessel parts (inlet piping, flow nozzles, substrate walls, flow guide vanes, filtration screens, collection nozzles). The parts are simple and few in number compared to solid walls. Note that filtration screens are assumed on the liquid collection nozzles since in most industrial applications such screens are prudent. In this case, foreign objects might include sensor pieces, vane pieces, oxide masses, buildup of insulator coating, weld slag, construction debris, etc.

There are some disadvantages for liquid walls. The primary disadvantage from a reliability point of view is that the substrate wall cannot tolerate loss of flow of the coolant for very long since the coolant is also the radiation shield. If liquid flow is lost, there will not be a means to remove heat for a short time, such as natural circulation. The substrate wall and/or vacuum vessel cooling system may not have enough thermal inertia to remove plasma heat before a quick shutdown. Therefore, instrumentation must be provided to monitor the flow and initiate quick plasma termination to avoid damage to the machine. This instrumentation would be similar to that used for solid wall in-vessel cooling, such as the system described by Stork (1998) or Hiroki (1999). Past nuclear applications have shown that single channels of safety instrumentation result in spurious signals that can erroneously shut down the system. Therefore, instrument voting logic is needed, comparing signals from multiple sensors and acting only when 2 of 3 , or 2 of 4 , signals agree. The multiple instruments must undergo periodic testing and maintenance to verify operability. If neutron activation of the substrate walls remains high, then some form of emergency pumping would be required to prevent thermal damage to the tokamak. An example of this is taken from the early ITER engineering design, where emergency power would drive 'pony motors' that would turn the main first wall pumps to produce a decay heat removal flow rate of $10 \%$ of the design flow rate. A refinement of that design idea was to use small, separate pumps designed for $10 \%$ of primary flow (Bartels, 1998). An alternative would be to increase the robustness of a vacuum vessel cooling system behind the substrate wall. If the liquid wall lost flow, the insulator coating would likely be damaged, giving downtime for repair, but the machine would not be compromised.

The upper bound reliability of a liquid wall system will be the reliability of the pumps used in the engineering flow loop. Since the wall must be flowing to establish heat removal and radiation shielding of the substrate walls, multiple pumps are a prudent reliability approach for redundancy. The redundant pumps must be physically separated to ensure that some common cause failure does not incapacitate all units. If the pumps were clustered a single room, a cause as simple as room air overheating could cause all the pump motors to fail. Pump power sources must be independent, and either uninterruptible or have fast-acting backup. The power requirement for the pumps could be high, which makes supplying backup power more difficult to accomplish, and probably more costly. While a loss of power to the system will likely cause a plasma 
termination due to loss of plasma control, the cooling of neutron activated parts must continue to remove decay heating. There are two choices for pumps, centrifugal or electromagnetic. Each offers good and bad points. Centrifugal pumps require impeller inspections for wear, and these pumps have been known to succumb to shaft binding from liquid metal frost buildup. Foreign material intrusion typically leads to pump damage (impeller imbalance, or in extreme cases, binding). A cover gas system is typically used to allow a positive shaft seal. Power consumption is modest and the pumps are easily designed for moving large flow rates. Large electromagnetic pumps are simple (no moving parts) and do not require only infrequent invasive inspections. Foreign material intrusion is not a great concern for these pumps. No cover gas is needed. Power consumption is generally higher than for centrifugal units, so operating costs can be higher. Wood (1991) discussed that liquid metal pumps have a longer breakin period than other mechanical equipment items, but Smith (1993) discussed that liquid metal pumps have an attractive longevity. There might be a pump cavitation concern in the liquid wall design; flow fluctuations at the collection nozzles could lead to flow pulsations and possibly cavitation. Cavitation is known to damage centrifugal pumps (Baladi, 1986).

Another disadvantage is found with the nozzles that deploy the liquid to the tokamak walls. These nozzles are subject to flow-induced erosion wear at the nozzle mouth. The nozzle must be specially designed to meet its design objective and to tolerate some nozzle wall material loss due to flow-induced erosion. The nozzles cannot drip any liquid metal coolant down into the plasma since that foreign material intrusion into the edge plasma will likely cause a disruption. Frequent disruptions will reduce power output and create excessive wear on the tokamak via electromagnetic forces and vibration.

The vessel interior will need periodic inspections to verify that the electrical insulation coatings are intact, the flow vanes are not wearing, and the nozzle openings are not wearing. Instruments that monitor wall operation also need periodic inspection and calibration. Solid walls require in-vessel inspections as well, but with modules being changed out on a periodic basis the inspections generally do not require great detail. Parts that continuously reside in the machine will require more detailed inspections.

\section{$3.4 \quad$ Results}

Overall, the most important issues from this failure modes and effects comparison are listed in order of importance below. The importance is based on a qualitative frequency and consequence judgment.

\section{Coolant pumping}

The liquid wall design is only as reliable as the pump units that supply the liquid. In solid walls, the large, thick in-vessel wall modules protect the vacuum vessel. Even in off-normal heating and cooling conditions, there are no concerns about vessel integrity. Any thermal or radiation damage is expended within these modules. Some solid wall designs use low afterheat materials (SiC afterheat reduces in a few minutes) so that decay 
heat is small and there is no need for active decay heat removal cooling. If a module were damaged by decay heat, it is designed for replacement. In liquid wall designs, maintaining the liquid wall layer is crucial to protecting the substrate and the vacuum vessel. Providing assured pumping is very important during plasma operation. If the liquid wall surface thermal load is as high as stated (up to $2 \mathrm{MW} / \mathrm{m}^{2}$ ) then the vacuum vessel cooling system [e.g., double walled vacuum vessel with annular cooling] could not remove enough heat to prevent wall damage if the liquid wall flow was greatly reduced or stopped in part of the machine. Basically, the Loss of Flow Accident (LOFA) would leave the vessel unprotected. The LOFA could lead to damage of the permanent structure (the substrate plates and possibly the vacuum vessel inner wall) before the plasma could be shut down. For this reason, the liquid wall availability is driven by the coolant pump reliability rather than the in-vessel component reliability. Pump trips are unlikely events, but the possibility of damage is high; therefore, some form of design precautions must be taken.

\section{Vacuum quality}

Current machine operations have demonstrated that solid wall systems can maintain reasonable vacuum cleanliness. The wall cooling system is designed to accommodate baking to drive out water vapor and other gases. The tokamak can also perform glow discharge cleaning and other techniques as part of commissioning to begin an operating run. There is erosion and sputtering of PFC surfaces during operation, so low atomic weight materials are used to reduce plasma energy losses. The coolant is contained, so from an operations perspective, the focus is on maintaining cleanliness of heat transfer surfaces, reducing tube plugging from oxide or other material buildup, and keeping pumps and instrumentation clear of foreign material. A standard purification system should suffice for this application, as it has for tokamak experiments and a variety of power plants. Liquid wall designs may also require vacuum vessel cleaning prior to coolant flow, but it is unknown how the electrical insulation coatings would respond to glow discharge cleaning or other in-vessel cleaning techniques. There may be no effect, or perhaps the surface could be slightly damaged. When the coolant does flow, there is a concern about a large-scale vacuum distillation effect releasing impurities into the plasma. Vacuum distillation is a laboratory process sometimes used for purifying liquid metals. To operate the liquid wall machine and achieve high availability, the liquid must be very pure. A robust coolant purification system is needed to treat a large percentage of the coolant as it flows around the system. Any equipment failures in the coolant purification system would likely lead to increased impurities in the vacuum chamber; enough degradation would lead to a forced outage to re-establish vacuum purity. Adding additional purification cold traps to the piping system increases the amount of equipment for inspections and adds more pressure boundary components. The liquid wall will also have some coolant evaporation, termed lithium frost, as well as sputtering. Operating the liquid lithium in fusion conditions (such as at the Current Drive Experiment-Upgrade at PPPL) is an important step to quantify the coolant purity issue, and verify that the wall can operate and be available for plasma operation.

Nozzle reliability 
A nozzle reliability issue raised by the liquid metal wall designers is that the nozzles must be "dripless". The only analogy for solid walls would be a pinhole leak that jetted coolant toward the plasma periphery. Solid wall designs are more robust to help prevent the pin hole leak events seen in present-day experiments. Nozzle wear is an important issue; if the nozzle mouth area were to increase due to flow-induced erosion from the 10 to $15 \mathrm{~m} / \mathrm{s}$ flow velocity and the slight expansion expected when the liquid traverses from low pressure flow to vacuum flow, the nozzles might require replacement. There would be downtime for replacement and pre-operational testing of the replacement unit. Another issue is that nozzle alignment would have to be verified periodically to assure proper wall coverage.

The flow nozzles in the liquid metal system might be required to oscillate for wall coverage. The solid wall design has no moving parts in the vacuum vessel, and past types of in-vessel diagnostics (retractable probes, etc.) have shown that moving parts in a vacuum have poor reliability. Lubricating oils typically do not function well in vacuum due to their vapor pressure, so greases have been used for diagnostics and remote handling equipment. The best approach for reliable oscillating nozzles would be units lubricated and driven by the coolant itself.

Maintenance downtime

Another issue of the solid versus liquid wall reliability is the downtime for refurbishment and component replacement. In the 1980's, solid wall components tested in high heat flux electron beam apparatus would fail before completing a test series. There has been a concerted effort to improve the reliability and longevity of these mock-ups, including feedback from field experience in operating tokamaks. The actively cooled wall armor modules can now withstand entire test series of repeated high heat flux pulses without degradation or failure. Advances in high temperature materials and in braze joining, together with design simplification, have led to reliability growth for these units. Future designs like ARIES-AT are projecting even simpler designs, so that replacement would be less frequent than in the past, and the downtime would be reduced. In-vessel module inspections may still be needed, and these could increase downtime. Plant availability estimates, for example the ARIES-AT design, have risen to the 80 to 90 percent range.

The liquid wall system design would still require in-vessel inspections for nozzle, vane, and substrate wall integrity, and possibly refurbishment of the electrical insulation coating on the substrate wall. In-vessel instrumentation may require periodic cleaning and calibration. Abdou has suggested that a first wall/blanket availability should be $97.8 \%$ or greater for an economically competitive power plant; and that the simple liquid wall designs show promise of meeting such values. For a calendar year, this allows only 8 days of scheduled plus unscheduled first wall/blanket outage. Consider that half the time should be set aside for unscheduled outages. Assuming around-the-clock operation, extensive remote inspection equipment, parallel path inspection of pump internals and the vacuum vessel components, parallel paths with other system inspections, and any other possible time-saving steps, four days is a short time. The inspection outage should fully 
inspect the vessel interior, verify coating effectiveness, perform operational checks of nozzles, replace any worn nozzles, recondition the vacuum vessel and vacuum system, and flow liquid coolant for pre-operational conditioning. Such effort might be possible to achieve by a large, seasoned plant operations staff having excellent outage planning, good procedures, and a matured plant. Liquid wall designs could have the reliability growth that would allow them to potentially meet this restrictive time interval.

\section{LOVAs}

This issue is the availability impact from an air ingress event. If the vacuum vessel were to suffer an extremely unlikely breach failure that allowed air into the vessel (i.e., a loss of vacuum accident or LOVA) during plant operation, the solid wall design would react by having a plasma disruption (Honda, 2000). The PFCs would be hot and could react with the oxygen in air until the walls were cooled. The wall cooling system would be intact unless the plasma disruption damaged some parts of the system. Even with damage and possible air-PFC reactions, the wall modules could be repaired and the surfaces refurbished. In a liquid wall system, the ingress air would be exposed to a very large surface of liquid metal. The coolant could be quickly drained to a holding tank to minimize chemical reactions with the inrushing air. The heat release from the chemical reaction is very high for some liquid metals, especially lithium. It is possible that the heat released could damage the machine interior (flow vanes, nozzles, substrate wall coatings, and perhaps the substrate wall itself). In addition, there would be some downtime for repairs and for coolant purification. The valves to the coolant holding tank would need to be quite reliable, since an inadvertent drain event would be very damaging to the machine.

\section{LOCAs}

This issue is consideration of extremely unlikely ex-vessel pipe failures. In the solid wall design, an ex-vessel pipe failure (loss of coolant accident, LOCA) without plasma shutdown leads to in-vessel tube overheat and probably burnout. The result is mobilization of both radioactive materials (tritium, activated corrosion products, activated dusts) and hazardous chemical dusts with potential release to the environment. In the solid wall system, the LOCA coolant inventory would be limited to one flow loop. In the liquid wall system, after air pressure equalizes in the vacuum vessel, it may be possible that more coolant from other loops could flow out of the break via gravity unless the design precludes such an event. No matter what the specific design, the coolant would likely have to be drained to the holding tank to minimize chemical reactions with ingress air. In the liquid wall design, accident progression is faster than the solid wall design. The breach allows air directly into the vessel. The releases to the reactor building would be hot coolant, coolant-air combustion products, released tritium from the coolant, and any activated impurities. If the liquid layer thickness is reduced by the LOCA flow before the plasma can be shut down or disrupts, substrate wall damage would likely occur, giving the same downtimes discussed above.

Helium pumping 
Another vessel cleanliness issue is vacuum pumping. Typically, liquid helium cryopumps are chosen for magnetic fusion use since they are very clean (no pump oil or lubrication concerns), operate without difficulty in magnetic fields, and have good pumping capacity for most gases. However, these pumps have a very low capacity for pumping helium. In solid wall designs, the excess deuterium and tritium from each gas puff fueling helps to entrain helium ashes into the vacuum pumps and cryotrap it in the vacuum pumps. There is a concern that the liquid walls will take up the deuterium and tritium into solution and these gases would not be available for cryotrapping helium ash. Vaporized lithium may perform the same entrainment function as the deuterium and tritium. The lithium frost might swamp the cryopump. Testing can determine if this concern would be a problem for a liquid wall power plant. If cryopumps are unacceptable, then effects of coolant vapor on other types of vacuum pumps must guide pump selection.

Natural circulation

The liquid wall design allows coolant to flow in a vacuum. Natural circulation flow is not possible from the top of the vacuum vessel to the bottom under vacuum conditions regardless of how the ex-vessel portion of the flow loop is designed or configured. Natural circulation has been regarded as a beneficial passive safety feature, and it allows relaxation of reliability requirements on the pump components. The liquid wall design could take advantage of low afterheat materials so that decay heat removal was not needed in the design; the pump system is already given extra requirements for functionality in normal operations. If high afterheat materials were used, then a decay heat removal system would be needed. 


\section{INHERENT RELIABILITY IN FABRICATION}

There are new developments that could have important effects on the reliability of both solid and liquid walls. Reliability of hardware in the field is based on many factors. Proper installation, operation, and maintenance are usually thought of as the most important factors. For a given type of component, this is generally true. However, if a component can be fabricated with more robustness, then its reliability in service is also improved. Many metal parts used in engineered cooling systems, such as valves, are manufactured by metal casting the basic shapes, then using metal finishing techniques to obtain desired surface finishes. Traditional arc welding is used for most weld joining applications. Buende (1995) argued that it was unlikely to improve existing manufacturing processes from the nuclear fission industry (i.e., there are no significant improvements left to make with a mature technology like arc welding), but there are design improvements that can be made to enhance weld reliability. Some of those ideas were two welds with a monitored interspace, extra weld passes for stronger joints, etc. There are also new technologies that fusion can use to its benefit, and also some advances in manufacturing and fabrication techniques for in-vessel components. Of course, strict quality assurance programs are needed to verify that the new techniques are correctly producing components. Operating experience has been used to shape design to meet the challenges of these components (Schlosser, 1998).

Table 5 shows typical fabrication processes; there are component failure rate data for the types of components listed in the table. However, that data collection for one fabrication process is not adequate to allow predictions of reliability for parts fabricated with new techniques. Literature was searched, and inquiries were made to both the reliability and manufacturing fields, to determine correlations between manufacturing and service reliability. No correlations of this type were found. Metallurgy and manufacturing tend to focus on specific problems in the field, such as meeting stress loads, marginalizing corrosion, etc., rather than the statistical reliability of mass produced parts. A study of correlating reliability with manufacturing method would be of interest to the engineering community.

There are a variety of heat treatments, oil baths, and post-fabrication processes (shot peening, etc.) that can increase the material strength from the traditional casting process. 
Table 5. Typical manufacturing techniques for cooling loop components

\begin{tabular}{|l|l|}
\hline \multicolumn{1}{|c|}{ Component type } & \multicolumn{1}{|c|}{ Manufacturing/fabrication approach } \\
\hline PFC tiles & $\begin{array}{l}\text { Forming depends on the tile material; the } \\
\text { tile is typically brazed to a substrate } \\
\text { surface Some in-vessel components are } \\
\text { hot isostatic pressed into shape. }\end{array}$ \\
\hline Nozzle & $\begin{array}{l}\text { Cast and weld, surface finish for } \\
\text { smoothness. }\end{array}$ \\
\hline Copper Tubing or Piping & Extrude, use brazes for joining. \\
\hline Small Diameter Steel Piping & $\begin{array}{l}\text { Extrude or hydroform (Hogarth, 1999), use } \\
\text { arc welds for joining. }\end{array}$ \\
\hline Large Diameter Steel Piping & $\begin{array}{l}\text { Typically, a flat plate is curled and seam } \\
\text { welded longitudinally. Large piping (1 m } \\
\text { diameter and greater) can be extruded, but } \\
\text { it is quite expensive. }\end{array}$ \\
\hline Bends and elbows of steel & $\begin{array}{l}\text { These can be extruded, or they can be } \\
\text { mechanically bent to shape. Extrusion } \\
\text { provides equal wall thicknesses. Arc welds } \\
\text { for joining. }\end{array}$ \\
\hline Gate Valve & $\begin{array}{l}\text { Cast the valve disk and body, machine the } \\
\text { shaft. Often special material inserts are } \\
\text { used for the wear surfaces. }\end{array}$ \\
\hline Globe valve & $\begin{array}{l}\text { Cast the body, machine the shaft. Special } \\
\text { materials are used for the shaft-to-surface } \\
\text { seal. }\end{array}$ \\
\hline Heat Exchanger & $\begin{array}{l}\text { Tubes are extruded, welded to the tube } \\
\text { sheet. The tube-to-tubesheet joints might } \\
\text { be explosion bonded. For small units, the } \\
\text { tube bunde is placed inside a large } \\
\text { diameter pipe. For large units, the shell is } \\
\text { constructed by welding curved plates. }\end{array}$ \\
\hline Centrifugal Pump & $\begin{array}{l}\text { Cast in plate shapes } \\
\text { mount; machine the shaft }\end{array}$ \\
\hline
\end{tabular}


Traditional casting of molten metal is pouring the metal into a mold, allowing it to cool and solidify, then opening or breaking the mold to remove the final part. Casting has the advantages of being able to produce complex shapes much quicker and easier than machining, easy production of very large parts, and easy production of shapes in metals that are hard to machine (DeGarmo, 1979). Casting began as a method used to obtain a basic shape for a metal part. The metal shape was then worked by other finishing means, such as grinding or polishing, to arrive at a final product. In the past, a wooden replica of the part was fashioned. The wooden replica was used to make the mold, especially in sand casting. Some foundries still use this method today, but more and more advanced techniques are being developed to produce highly accurate replicas and molds that can repeatedly produce near net shape parts. Near net (or near finished) shape means that the cast part is very close to exact dimensions and surface smoothness needed so very few other operations are required (Campbell, 2000). Obviously, near net shape means faster production of parts (less work needed after casting) so there is an economic incentive in developing this technology. There may be some reliability issues with the material strength of the cooled metal and good surface finish presenting fewer sites for microcrack initiation. A typical foundry process is to pull some samples from a production lot and test them to confirm that the cast parts have comparable strength to wrought (shaped by plastic deformation) parts.

A very promising new technique for component fabrication is laser forming (Waganer, 2000a). It is also called direct light fabrication. Laser forming can now operate from a computer aided design drawing and produce the component (Smugeresky, 1997; Thoma, 1995), without the traditional casting steps of constructing a prototype, then making a mold, and finally casting the component. Laser forming uses a base plate of metal as a starting point. Metal powder is introduced in a controlled gas atmosphere and a laser is used to melt the metal powder so that it forms the necessary surface features that the part requires. Having a laser make multiple passes to build up a three dimensional shape appears to make the final part stronger, having formed many grain layers in the material as each laser pass has deposited a very thin layer of melted metal powder. For metals, typically high strength is obtained by even dispersion of many small grains that resist stress and strain placed on the metal shape (Budinski, 1989). Some laser near net shape forming has produced metal parts with yield strengths about $20 \%$ higher than the same parts created by traditional casting techniques; this is attributed to the grain size and phase transformation in the solidification process (Schlienger, 1998). The surface finishes tend to be quite good (i.e., smooth) without additional work such as grinding or polishing. Parts produced with higher strengths and good surface finishes to resist erosion-corrosion should exhibit higher service reliability than traditional parts. However, the data have not yet been taken to quantify how much of a reliability gain can be achieved. The gains that are discussed are speed in manufacturing, so that parts are produced less expensively, and accuracy of forming, so that parts require less surface work (grinding, polishing, etc.) to complete their fabrication. Fusion components tend to require precision manufacturing, so accuracy in forming is an important consideration. The metal powder flow can be reduced to give more smooth surfaces (Smugeresky, 1997a). A smoother surface means less surface work (i.e., grinding or polishing, etc.) is needed, so there are fewer operations performed per part and less part handling, hence 
less expense per part. Cost is important to fusion designs, especially solid wall designs where replacements are needed. Selecting an appropriate surface finish is important for substrates where a coating must be adhered.

One of the issues with liquid walls is having the introduction nozzles remain in tolerance while under high flow rates; that is, good wear resistance of the nozzles. The laser forming system can easily adjust the metal powder alloying element concentrations gradually, so that the material properties of the finished product are changed gradually rather than relying on abrupt changes, such as an exterior cladding of protective material that is added later in the fabrication process. A metal powder change (Griffith, 1997) may be used when forming the nozzle opening to strengthen it against flow-induced erosion while keeping the dimensions very accurate. For the solid wall design, the walls can be formed over mandrels to make integral cooling channels instead of drilling cooling channels in a block. The channel walls will be thicker than copper tubing walls, so the incidence of through wall cracks would, in general, be reduced. The same metal powder composition change could be used to enhance weldability of piping header to the ends of the integral coolant channels of a monoblock. These design enhancements would mean that the presently seen leak rates in experimental tokamaks would be greatly reduced for matured power plants.

Another forming process is by laser melting of wire feed rather than metal powder feed (Griffith, 1997a). A drawback of the laser melting metal powder is that much of the powder must be recycled, perhaps only $20 \%$ will melt in the pool that solidifies to make up the metal part under production. While the laser and powder system is actually quite fast, the wire feed system boasts that it can construct parts faster than the other process. The wire feed approach is less amenable to blending metal properties.

The hot isostatic press (HIP) technique has been used in fusion as well. Stainless steel for an ITER blanket/shield module used a HIP process (Febvre, 1996). The HIP is considered to be a reference process for joining steel to steel, copper to copper, and copper to steel, and armor material to copper heat sink for ITER (Tavassoli, 1998). This technique is used in many applications of powder metallurgy for many types of industrial and aerospace equipment. Rapid solidification in powder metallurgy can be used with HIP, and can be used with extrusion techniques as well. The yield strengths of metal alloys can be increased by $1 \%$ up to nearly $30 \%$ over traditional casting (German, 1994). In HIP, a powdered metal is heated and pressurized gas (often argon gas is used) compressed to form a component shape.

An important part of this discussion is how the designer must treat parts and components. For large mechanical components such as those used in a flow loop, the designer is given direction in the American Society of Mechanical Engineers (ASME) Boiler and Pressure Vessel Code and the ASME B31 series of piping codes. The designer is directed to use average material strengths from tables in the code, based on testing of components manufactured by traditional techniques (i.e., casting, forming, and arc welding). A yield strength value is chosen based on the type of material and the fabrication process that the designer is specifying for the part. The designer is also directed to apply stated safety 
factors to components in various applications. If a component can be made with higher inherent material strength, there are two courses of action. The code can be revised to acknowledge this new means of fabrication and include a new average material strength that reflects the increased strength of the fabrication technique, or the designer can continue to use existing codes applied to the component fabricated by the new technique. In the former case, the designer may wait for years while the code committee collects enough data for analysis, drafts an amendment, obtains design community review of the amendment, regulatory body review, etc., to approve an amendment to the code. In the latter case, the designer will be allowing an extra margin of safety into the system design, since the new component with higher strength than comparable components is treated like the traditional component with average strength. Therefore, until these new manufacturing methods warrant inclusion in ASME and other codes, it is reasonable to assume that components fabricated with laser forming will have fractionally higher safety margins. This is a safety advantage while still keeping manufacturing costs low. This advantage applies to both liquid wall and solid designs, since the techniques can make stronger parts for each design.

Braze technology has been studied as well. The use of an intermediate layer between the two elements (the PFC and substrate) appears to be promising in fabricating stronger brazed joints for tiles (Odegard, 1998). There are good programs to track braze quality before use in a tokamak as well (Nygren, 1995). 


\section{CONCLUSIONS}

The basic solid wall approach and liquid wall approach have been compared for qualitative reliability. There have been claims that the reliability and ease of maintenance of liquid walls should dictate that the liquid designs are more promising and better suited to future tokamaks than solid wall designs. While the in-vessel portion of the liquid wall system is less complicated and has fewer components than a solid wall system, the liquid wall dependency on ex-vessel pumps means that the upper bound on the system reliability is limited by the failure rate of the pump or set of pumps. More work on engineering design should be done on the ex-vessel portion of the liquid wall concept.

Each design approach has strong points and weak points. The comparisons in Tables 2, 3 , and 4 showed these strengths and weaknesses. A strength of the solid wall systems is that the initial reliability problems with brazed and welded joints have been recognized. Several fusion programs around the world are investigating methods to increase the reliability of these joints so that the modules are leak tight and have longer lifetimes with good success. Different design ideas are tested in electron beam testing facilities in the US and abroad. The solid wall approach has shown a reliability growth from the 1980's when mock-up samples failed during testing to the 1990's when advanced materials and new designs have completed entire high heat flux test series without degradation.

The main strength of the liquid wall system is its in-vessel simplicity. There are many issues to be resolved for the liquid wall system, including pump reliability, coolant purity (vacuum cleanliness), nozzle reliability, behavior in a LOVA and LOCA, pumping helium from the vacuum chamber, and if natural circulation is needed from a reliability/safety perspective. The liquid wall engineering design could address these issues.

Table 4 showed that the approaches ranked equally in the features used to determine a qualitative level of reliability in engineering designs. In that table, the solid wall systems had advantages of operating experience feedback and good component testing programs. The liquid wall systems had the advantages of a true minimum of in-vessel parts and the beginning of a strong testing program.

The liquid wall idea should be investigated for its merits, and the possibility of use in divertors conjunction with solid first walls, as in the ALPS task (Mattas, 1999). However, until more work is done to develop the concept further to allow better judgments of its strengths and weaknesses and a quantitative reliability assessment, it should not be thought of as a replacement for solid wall designs. 


\section{References}

Abdou, 1999. M. A. Abdou and the APEX Team, "Exploring novel high power density concepts for attractive fusion systems," Fusion Engineering and Design, 45, 1999, pages $145-167$.

Abdou, 2000. M. Abdou, "Brief Overview of APEX," presentation at the APEX/HPD Workshop, Tokyo, Japan, February 21-23, 2000. Available from the Advanced Power Extraction web site, http://www.fusion.ucla.edu/APEX.

Abramson, 1976. R. Abramson et al., "Evolution of Sodium Purification, Rapsodie, Phenix, Super-Phenix," Proceedings of the International Conference on Liquid Metal Technology in Energy Production, Champion, PA, May 3-6, 1976, CONF760503-P1, November 1976.

Anderson, 2000. M. H. Anderson and M. L. Corradini, "Experimental Behavior of Molten Sn(x)Li(y) when Impacted by a Column of Water," presented at the $14^{\text {th }}$ Topical Meeting on the Technology of Fusion Energy, Park City, Utah, 15-19 October, 2000. To be published in the Fusion Technology journal.

Baker, 1980. C. C. Baker et al., STARFIRE - A Commercial Tokamak Fusion Power Plant Study, ANL/FPP-80-1, Argonne National Laboratory, September 1980.

Baladi, 1986. J. Y. Baladi and C. P. Nyilas, Development of a Cavitation Free Sodium Pump for the Breeder Reactor, Westinghouse Electric Corporation, CONF 86121122, ASME Winter Meeting, Anaheim, CA, December 7, 1986.

Bangs, 1986. S. Bangs, "When a weld fails .... the catastrophic explosion of a highpressure steam line at the Mohave Edison power plant could mean the end of welded pipe for this application worldwide," Welding Design \& Fabrication, March 1986, pages 79-82.

Bartels, 1998. H.-W. Bartels et al., "ITER Reference Accidents," Fusion Engineering and Design, $\underline{42}$, 1998, pages 13-19.

Bongarra, 1985. J. P. Bongarra et al., Human Factors Design Guidelines for Maintainability of Department of Energy Nuclear Facilities, UCRL-15673, Lawrence Livermore National Laboratory, June 1985, section 3.2.4.5.

Bretherick's, 1999. P. G. Urben et al., editors, Bretherick's Handbook of Reactive Chemical Hazards, volume $1,6^{\text {th }}$ edition, Butterworth Heinemann, Oxford, 1999, pages $1749-1758$.

Budinski, 1989. K. Budinski, Engineering Materials, Properties and Selection, third edition, Prentice Hall, Englewood Cliffs, NJ, 1989, chapter 13. 
Buende, 1995. R. Buende, "Reliability, availability, and quality assurance considerations for fusion components," Fusion Engineering and Design, 29, 1995, pages 262285.

Cadwallader, 1987. L. C. Cadwallader and D. F. Holland, "Incorporating Reliability into the Design of Experimental Fusion Facilities," Proceedings of the 12th Symposium on Fusion Engineering, Monterey, CA, October 1987, IEEE Catalog No. 87CH2507-2, pages 1262-1266.

Cadwallader, 1999. L. C. Cadwallader and D. A. Petti, "A Review of Availability Growth in Energy Production Technologies," Proceedings of the $18^{\text {th }}$ Symposium on Fusion Engineering, October 25-29, 1999, Albuquerque, New Mexico, IEEE, pages 585-588.

Campbell, 2000. J. Campbell, "The Concept of Net Shape for Castings," Materials and Design, 21, 2000, pages 373-380.

Castro, 1998. R. G. Castro et al., "Fabrication and high heat flux testing of plasmasprayed beryllium ITER first wall mock-ups," Journal of Nuclear Materials, 258263, 1998, pages 252-257.

Cerdan, 1998. G. Cerdan et al., "R.H. divertor maintenance - Divertor refurbishment platform," Fusion Technology 1998, Proceedings of the $20^{\text {th }}$ Symposium on Fusion Technology, 7-11 September 1998, Marseille, France, CEA, 1998, pages 1115-1118.

Citrolo, 1993. J. C. Citrolo and J. Chranowski, "TPX Superconducting Magnet Fabrication Process," Proceedings of the $15^{\text {th }}$ Symposium on Fusion Engineering, San Diego, CA, 1993, pages 798-801.

Cote, 1992. A. E. Cote and J. L. Linville, Fire Protection Handbook, $17^{\text {th }}$ Ed., National Fire Protection Association, Quincy, MA (1992) section 3, chapter 1.

Croessmann, 1988. C. D. Croessmann and J. B. Whitley, "High Heat Flux Testing of Plasma Facing Components for Tore Supra," Fusion Technology 1988, Proceedings of the $15^{\text {th }}$ Symposium on Fusion Technology, Utrecht, The Netherlands, 19-23 September, 1988, North-Holland, Amsterdam, pages 796-802.

Cusak, 1998. R. Cusak et al., "Operational Experience from the JET Remote Handling Tile Exchange," Fusion Technology 1998, Proceedings of the $20^{\text {th }}$ Symposium on Fusion Technology, 7-11 September 1998, Marseille, France, CEA, 1998, pages 1135-1138.

DDR, 1997. Technical Basis for the ITER Detailed Design Report, Cost Review and Safety Analysis (DDR), ITER EDA Documentation Series No. 13, International Atomic Energy Agency, Vienna, December 1997, Chapter II, Section 6. 
DeGarmo, 1979. E. P. DeGarmo, Materials and Processes in Manufacturing, fifth edition, MacMillan Publishing Co., New York, 1979, chapter 11.

Deksnis, 1997. E. B. Deksnis et al., "Beryllium plasma-facing components: JET Experience," Fusion Engineering and Design, 37, 1997, pages 515-530.

Doerner, 1997. R. Doerner and C. Mays, "Beryllium dust generation resulting from plasma bombardment," Fusion Engineering and Design, 37, 1997, pages 325-331.

Febvre, 1996. M. Febvre et al., "Solid HIPed Demonstration of ITER Blanket-Shield Modules," Fusion Technology 1996, Proceedings of the $19^{\text {th }}$ Symposium on Fusion Technology, Lisbon, Portugal, 16-20 September 1996, pages 1311-1314.

German, 1994. R. M. German, Powder Metallurgy Science, Metal Powder Industries Federation, Princeton, NJ, 1994, chapter 3.

Griffith, 1997. M. L. Griffith et al., Multi-Material Processing by LENS, SAND971496C, Sandia National Laboratory, December 1997.

Griffith, 1997a. M. L. Griffith, Materials and Properties of Components formed Using the 3DWire Process, SAND97-3116C, Sandia National Laboratory, December 1997.

Hiroki, 1999. S. Hiroki et al., "Leak detection system in ITER," Fusion Engineering and Design, 46, 1999, pages 11-26.

Hogarth, 1999. S. Hogarth, "Tubular Hydroforming: Riding the Wave," Manufacturing Engineering, 123, October 1999, pages 78-83.

Holmes, 1977. J. T. Holmes et al., "Sodium Purification by Cold Trapping at the Experimental Breeder Reactor II," Nuclear Technology, 32, March 1977, pages 304-314.

Honda, 2000. T. Honda et al., "Analyses of loss of vacuum accident (LOVA) in ITER," Fusion Engineering and Design, 47, 2000, pages 361-375.

Kato, 1998. Y. Kato et al., "Impurity Control in liquid lithium loop for IFMIF target facility," Journal of Nuclear Materials, 258-263, 1998, pages 394-399.

Katsuta, 1977. H. Katsuta et al., "Equilibrium Pressure and Solubility of Hydrogen in Liquid Lithium," Nuclear Technology, 32, March 1977, pages 297-303.

Katsuta, 1998. H. Katsuta et al., "Present Status of the Conceptual Design of IFMIF Target Facility," Journal of Nuclear Materials, 258-263, 1998, pages 388-393. 
Kishimoto, 1998. H. Kishimoto, M. Kagami, and M. Kikuchi, "Recent Results and Engineering Experiences from JT-60," Fusion Engineering and Design, 39-40, 1998, pages 73-81.

Kolowith, 1985. R. Kolowith, J. D. Berg, and W. C. Miller, Experimental Lithium System, Final Report, HEDL-TME-84-29, Hanford Engineering Development Laboratory, April 1985.

Liao, 1992. C. Liao and M. S. Kazimi, "A Feasibility Assessment of Liquid Metal Divertors," Fusion Technology, 21, May 1992, pages 1845-1851.

Marmy, 1990. P. Marmy, D. Ringer and U. Stiefel, "Friction and wear in the hostile environment of a tokamak," Fusion Engineering and Design, 13, 1990, pages 307311.

Mattas, 1999. R. F. Mattas et al., "ALPS - Advanced Limiter-divertor Plasma-facing Systems," ANL/TD/CP-98438, presented at the International Symposium on Fusion Nuclear Technology, Rome, Italy, 19-24 September, 1999.

McCarthy, 1996. K. A. McCarthy et al., "Summary of oxidation driven mobilization data and their use in fusion safety assessments," Journal of Nuclear Materials, 233237, 1996, pages 1607-1611.

McCown, 1980. J. J. McCown et al., FFTF Sodium and Cover Gas Characterization and Purification, HEDL-SA-1874-FP, Hanford Engineering Development Laboratory, February 1980.

Merola, 1998. M. Merola and G. Vieider, "On the use of flat tile armour in high heat flux components," Journal of Nuclear Materials, 258-263, 1998, pages 672-676.

Merrill, 1991. B. J. Merrill and S. C. Jardin, "Coolant Ingress Induced Disruption Calculations for ITER,” Fusion Technology, 19, May 1991, pages 1278-1283.

Mills, 1999. S. F. Mills et al., "Remote Handling of JET In-Torus Components - A Practical Experience," Proceedings of the $18^{\text {th }}$ IEEE/NPSS Symposium on Fusion Engineering, October 25-29, 1999, Albuquerque, New Mexico, 1999, pages 151154.

Moir, 1995. R. W. Moir, "The logic behind thick, liquid-walled, fusion concepts," Fusion Engineering and Design, 29, 1995, pages 34-42.

Moir, 1997. R. W. Moir, "Liquid First Walls for Magnetic Fusion Energy Configurations," Nuclear Fusion, 37, 1997, pages 557-566. 
Morley, 1995. N. B. Morley and M. A. Abdou, "Modeling of fully-developed, liquid metal, thin film flows for fusion divertor applications," Fusion Engineering and Design, 29, 1995, pages 339-356.

Natesan, 1995. K. Natesan, "Fabrication and Performance of AlN Insulator Coatings for Application in Fusion Reactor Blankets," ANL/ET/CP-86420, CONF-950961-8, September 1995.

Nygren, 1995. R. E. Nygren et al., "Assessing braze quality in the actively cooled Tore Supra phase III outboard pump limiter," Fusion Engineering and Design, 28, 1995, pages 113-118.

Odegard, 1998. B. C. Odegard Jr. et al., "A review of the US joining technologies for plasma facing components in the ITER fusion reactor," Journal of Nuclear Materials, 258-263, 1998, pages 329-224.

O'Hanlon, 1989. J. F. O'Hanlon, A User's Guide to Vacuum Technology, John Wiley \& Sons, Inc., New York, 1989, chapter 15.

Petti, 2000. D. A. Petti et al., "Safety and Environmental Results for the ARIES-AT Design," presented at the $14^{\text {th }}$ Topical Meeting on the Technology of Fusion Energy, Park City, Utah, 15-19 October, 2000. To be published in Fusion Technology journal.

Pinna, 1998. T. Pinna et al., "Failure mode and effect analysis on ITER heat transfer systems," Fusion Engineering and Design, 42, 1998, pages 431-436.

Rödig, 1998. M. Rödig et al., "Testing of actively cooled high heat flux mock-ups," Journal of Nuclear Materials, 258-263, 1998, pages 967-971.

Rognlien, 2000. T. D. Rognlien, "Task A: Plasma/Liquid Surface Interactions and Plasma-Edge Modeling," presented at the $2^{\text {nd }}$ Electronic APEX Meeting, August 17, 2000, available at the web site http://www.fusion.ucla.edu.

SADL2, 1997. Safety Analysis Data List, version 2.0, ITER Joint Central Team, S 81 RI 18 97-05-04 W0.1, San Diego Joint Work Site, May 1997.

Schlienger, 1998. E. Schlienger et al., Near Net Shape Production of Metal Components using LENS, SAND-98-0664C, Sandia National Laboratories, March 1998.

Schlosser, 1998. J. Schlosser et al., "Design, fabrication and testing of an improved high heat flux element, experience feedback on steady state plasma facing components in Tore Supra," Fusion Engineering and Design, 39-40, 1998, pages 235-240. 
Schnauder, 1997. H. Schnauder, C. Nardi, and M. Eid, "Comparative availability analysis of the four European DEMO blanket concepts in view of the selection exercise," Fusion Engineering and Design, 36, 1997, pages 343-365.

Smid, 1998. I. Smid et al., "Development of tungsten armor and bonding to copper for plasma-interactive components," Journal of Nuclear Materials, 258-263, 1998, pages 160-172.

Smith, 1993. M. S. Smith et al., "Assessment of liquid-metal centrifugal pumps at three fast reactors," Nuclear Technology, 104, 1993, pages 118-127.

Smugeresky, 1997. J. E. Smugeresky et al., Using the Laser Engineered Net Shaping (LENS) Process to Produce Complex Components from a CAD Solid Model, SAND97-8546, Sandia National Laboratory, August 1997.

Smurgeresky, 1997a. J. E. Smugeresky et al., Laser Engineered Net Shaping (LENS) Process: Optimization of Surface Finish and Microstructural Properties, SAND97-8652C, Sandia National Laboratory, December 1997.

Stork, 1998. D. Stork et al., "Interlock and protection systems for JET in-vessel cooling and cryogenic components," Fusion Technology 1998, Proceedings of the $20^{\text {th }}$ Symposium on Fusion Technology, 7-11 September 1998, Marseille, France, CEA, 1998, pages 571-574.

Surle, 1998. F. Surle et al., "The Tore Supra Cooling System: 10 years of operation," Fusion Technology 1998, Proceedings of the $20^{\text {th }}$ Symposium on Fusion Technology, 7-11 September 1998, Marseille, France, CEA, 1998, pages 665-668.

Suzuki, 1994. S. Suzuki et al., "High heat flux experiments of saddle type divertor module," Journal of Nuclear Materials, 212-215, 1994, pages 1365-1369.

Sze, 1995. D.-K. Sze et al., "Tritium Recovery from Lithium, Based on a Cold Trap," Fusion Engineering and Design, 28, 1995, pages 220-225.

Sze, 1998. D.-K. Sze et al., "The ARIES-RS Power Core - Recent Development in Li/V Designs," Fusion Engineering and Design, 41, 1998, pages 371-376.

Sze, 1999. D.-K. Sze et al., "Sn-Li, A New Coolant/Breeding Material for Fusion Applications," ANL/TD/CP-98464, Argonne National Laboratory, presented at the $9^{\text {th }}$ International Conference on Fusion Reactor Materials, Colorado Springs, CO, October 10-15, 1999.

Tada, 1998. E. Tada et al., "Development of remote maintenance equipment for ITER blankets," Fusion Engineering and Design, 42, 1998, pages 463-471. 
Tavassoli, 1998. A-A.F. Tavassoli, "Overview of advanced techniques for fabrication and testing of ITER multilayer plasma facing walls," Fusion Engineering and Design, 39-40, 1998, pages 189-200.

Thoma, 1995. D. J. Thoma et al., Directed Light Fabrication of Iron-based Materials, LA-UR-95-4194, Los Alamos National Laboratory, 1995.

Thome, 1998. R. J. Thome et al., "ITER Central Solenoid Model Coil Fabrication and Implications for the Full Scale Central Solenoid," Fusion Technology 1998, Proceedings of the $20^{\text {th }}$ Symposium on Fusion Technology, 7-11 September 1998, Marseille, France, CEA, 1998, pages 803-806.

Tillack, 2000. M. S. Tillack, “Overview of ARIES Engineering Activities," Presentation at the ARIES Program Peer Review, held at UCSD, August 17, 2000, available at the Fusion Energy Research Program page http://www-ferp.ucsd.edu/.

Waganer, 1999. L. Waganer, "Innovative, Ultra-Low Cost Fabrication Methods," Proceedings of the $18^{\text {th }}$ IEEE/NPSS Symposium on Fusion Engineering, Albuquerque, New Mexico, October 25-29, 1999, IEEE, pages 77-80.

Waganer, 2000. L. M. Waganer, "Power Core Maintenance Approach and Maintainability Analysis," Presentation at the ARIES Project meeting held at PPPL, September 18-20, 2000, available at the Fusion Energy Research Program page http://www-ferp.ucsd.edu/. See also L. M. Waganer, "Comparing Maintenance Approaches for Tokamak Fusion Power Plants," presented at the $14^{\text {th }}$ Topical Meeting on the Technology of Fusion Energy, to be published in Fusion Technology journal.

Waganer, 2000a. L. M. Waganer, "Advanced Manufacturing and Power Core Maintainability," Presentation at the ARIES Program Peer Review, held at UCSD, August 17, 2000, available at the Fusion Energy Research Program page http://www-ferp.ucsd.edu/.

Wood, 1991. D. H. Wood et al., "Assessment of Early, Useful, and Wear Out Operating Periods for Liquid-Metal Centrifugal Pumps," Transactions of the American Nuclear Society, 63, 1991, pages 278-279.

Yevick, 1966. J. G. Yevick and A. Amorosi, editors, Fast Reactor Technology: Plant Design, MIT Press, Cambridge, MA, 1966, chapter 3.

Ying, 1999. A. Y. Ying et al., "Free Surface Heat Transfer and Innovative Designs for Thin and Thick Liquid Walls," presented at the International Symposium on Fusion Nuclear Technology (ISFNT5), Rome, Italy, September 1999. Available at the web site http://www.fusion.ucla.edu/APEX.

Youssef, 2000. M. Z. Youssef et al., "Nuclear Performance of the Thin-Liquid FW Concept of the CLiFF Design," presented at the $14^{\text {th }}$ Topical Meeting on the 
Technology of Fusion Energy, Park City, Utah, 15-19 October, 2000. To be published in Fusion Technology journal, March 2001. 
APPENDIX A

QUALITATIVE RELIABILITY IN DESIGN 


\section{APPENDIX A: QUALITATIVE RELIABILITY IN DESIGN}

This appendix contains information on the failure modes and effects analysis (FMEA) comparative study of solid and liquid walls, and discussions on reliability in the engineering design of systems. The FMEA is a step-by-step analysis technique where the modes or ways a component can fail are identified and the consequences of those failures are also identified and addressed. The FMEA is used in many industries, including the aerospace industry (NASA, 1988), the chemical process industry (CCPS, 2000), the electronics industry (IEC, 1985), the automotive industry (SAE, 1995), the fission power industry (IEEE, 1987), the military equipment production industry (MIIL, 1991), and even fusion research (Pinna, 1998). The FMEA is a step-by-step analysis procedure that gives a complete view of each major component in a system design. The goal of the FMEA is to identify potential weaknesses in the design and correct them before such weaknesses are too entrenched in the design to easily make changes.

Table A-1 gives the comparative FMEA for the solid and liquid wall systems. The designs are generic since the solid wall has many detailed designs to choose from while the liquid wall design is only in the conceptual design stage. The results of the FMEA process are discussed in the body of this report.

The discussion of reliability in design follows the pages of Table A-1. 


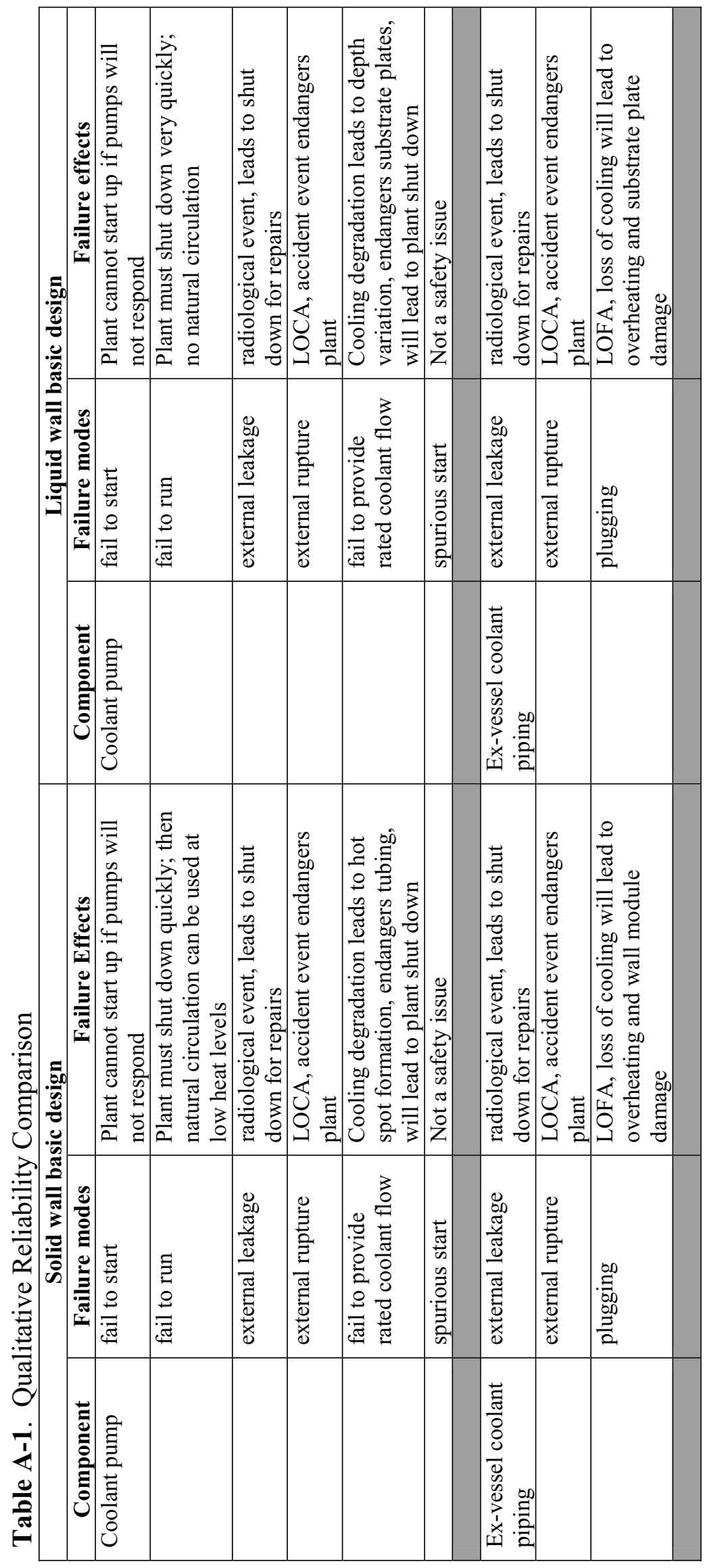









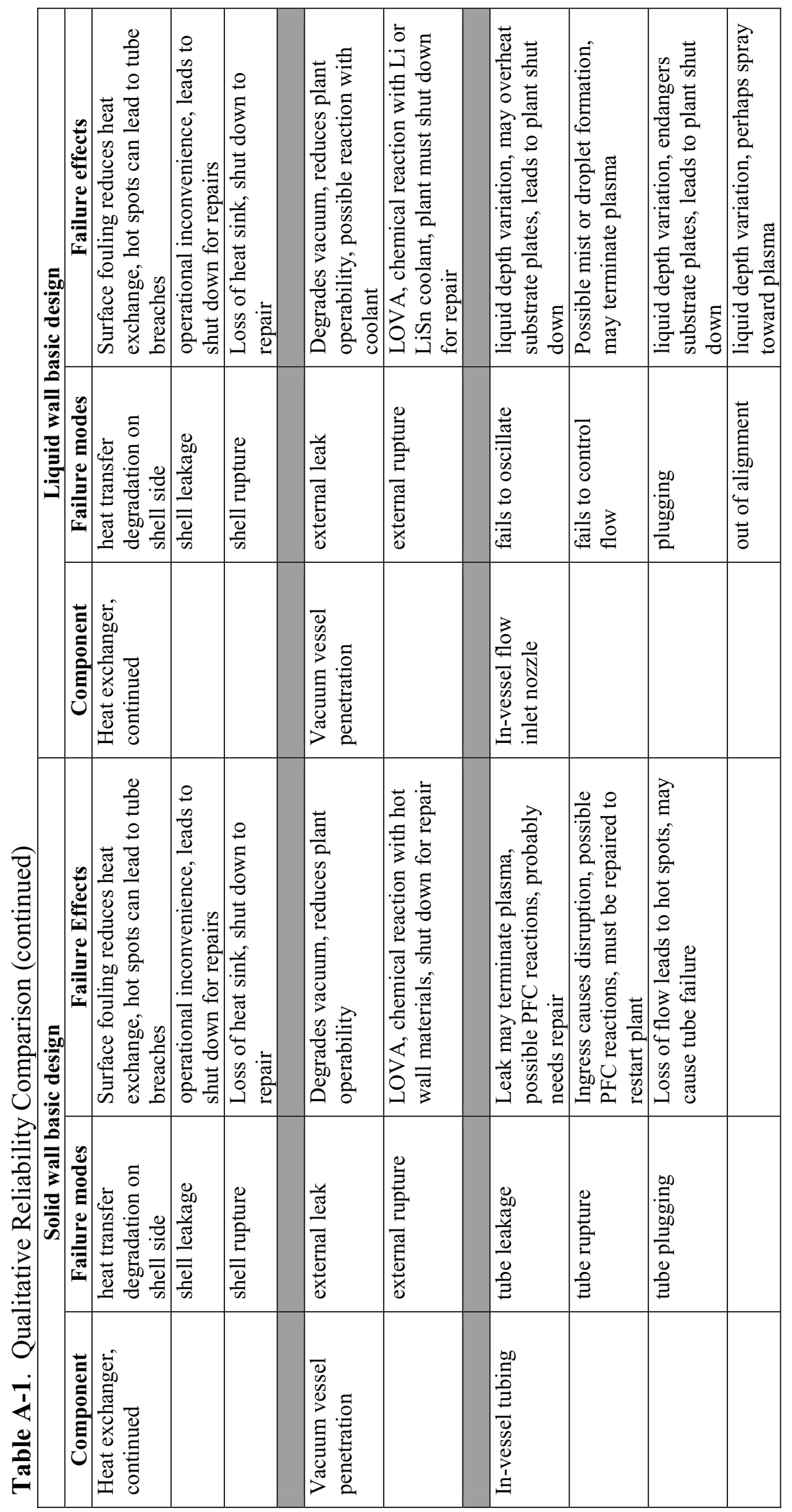




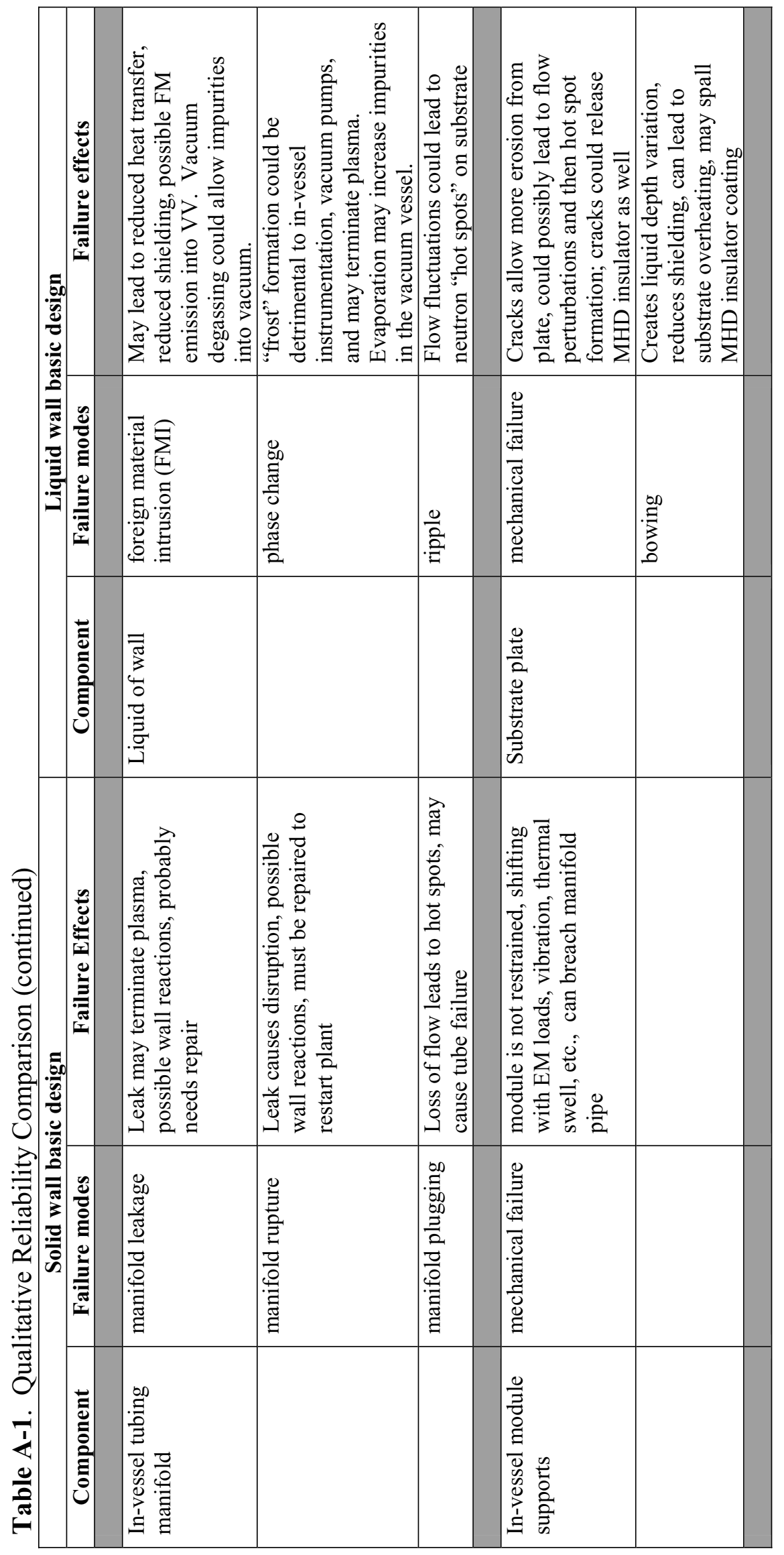




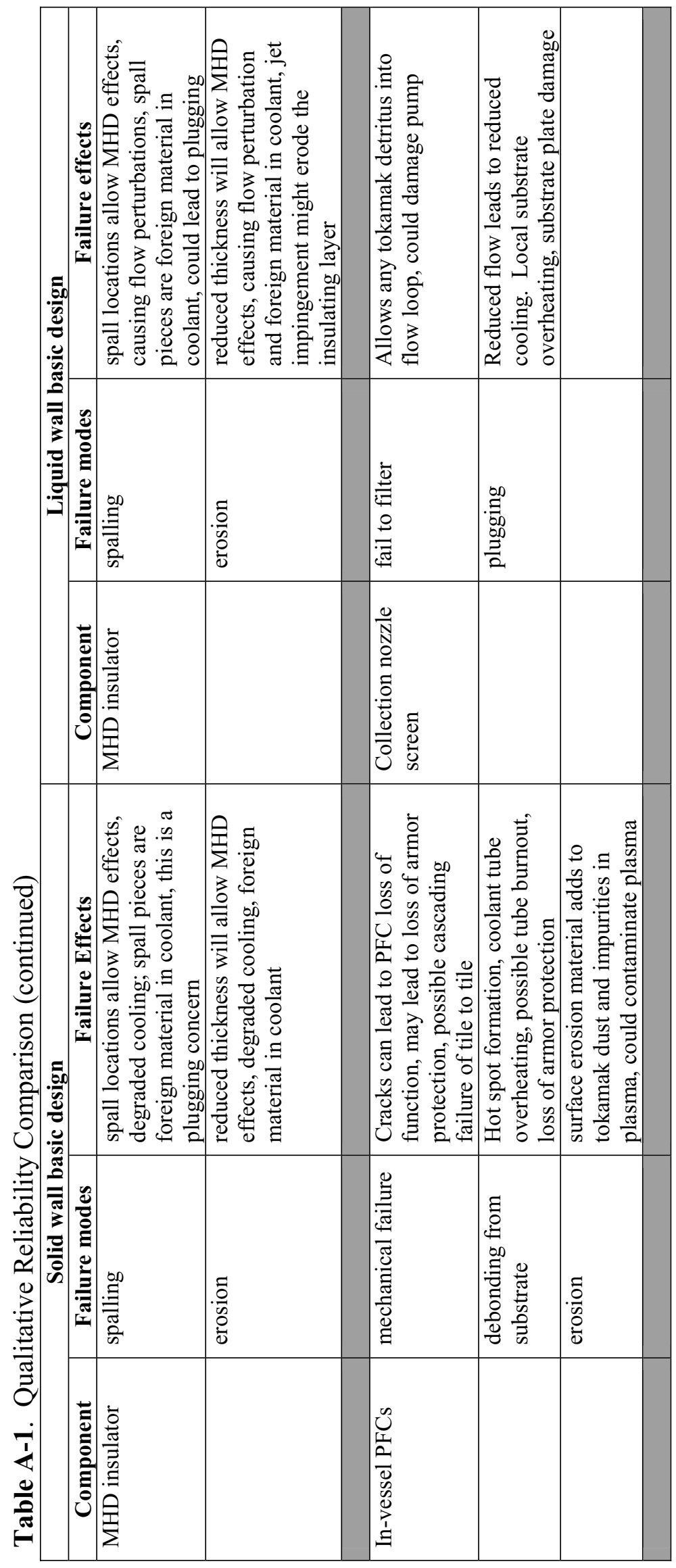




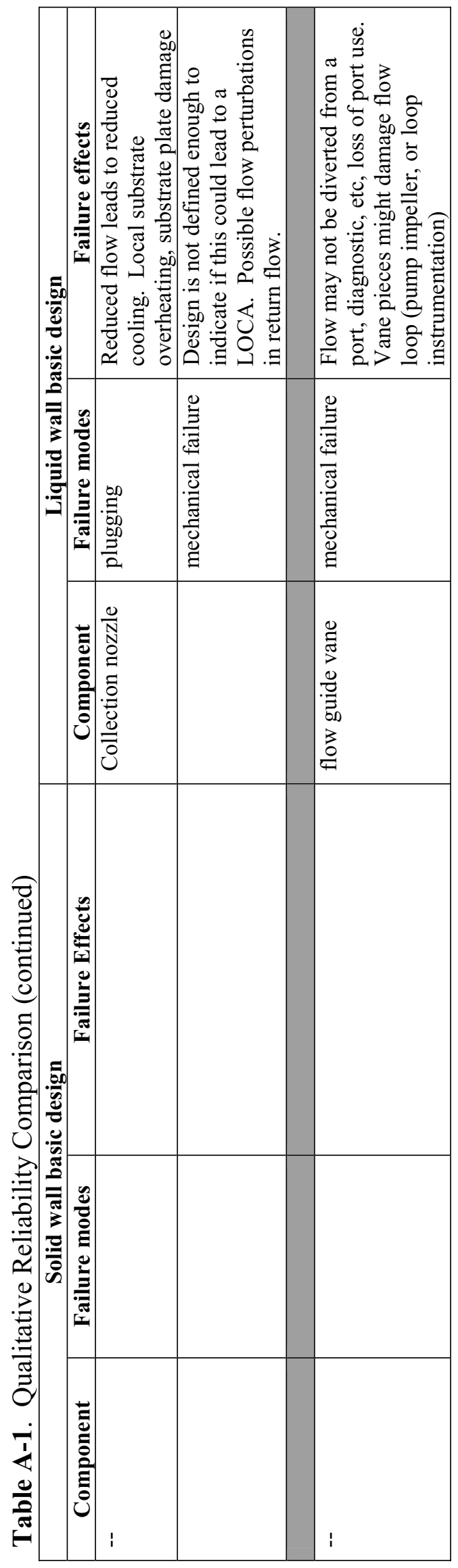




\section{Reliability in Design}

In engineering design, reliability is a factor to be considered. Quantitative reliability; that is, statistical estimation of component life, can be assessed by a variety of means. These means include: using estimation via guidelines and handbooks (MIL, 1991; Bellcore, 1992; NSWC, 1992), inferring a value from operating experience of similar components in similar applications (Cadwallader, 1996), accelerated life testing, manufacturer testing programs, and directly collecting field experience data on components already in use (if there are any components already in use). Qualitative reliability is the consideration of component modes of failure, and for the purposes of this report, also includes component design principles and manufacturing practices.

Qualitative aspects of component reliability in the design process can be expressed by two main ideas. These ideas are: 1) use the fewest number of parts possible, and 2) ensure that each part is as reliable as possible (Caplen, 1972). The first idea is the expression of the time-honored adage that "what is not there cannot fail". Of course, economic factors in the design activity also motivate designers to use the fewest number of components or parts to achieve the design objective for a system. Unfortunately, other factors such as public safety concerns, system complexity needs to meet design objectives, system cross-connections, etc., cause the number of components to increase. Recent industrial designs in general illustrate that many components and systems are performing multiple design functions, interacting with other systems at multiple interface points, achieving higher throughputs than past systems, and are using sophisticated controls for efficiency. Other performance requirements or improvements also add complexity and more parts to the major components or systems. The designer must make the first of many trade-offs between system versatility, robustness, and complexity, reliability, safety, environmental protection, and economics. The designer also must deal with design evolution over time. Often the first design proves its adequacy as a functional, or workable, design with a modest number of parts. Later, the system or component design is augmented or changed to optimize some important parameter, improve its interface with other systems, or meet additional objectives. The important parameter might be energy efficiency, throughput, or another value related to economics of the overall process. Optimization on an important parameter could increase or decrease numbers of parts.

The second idea of ensuring that the design of each part or subcomponent is reliable can be achieved by a number of methods or approaches. The widely used methods are listed in Table A-2. These methods are qualitative, and have varying degrees of quantitative 
Table A-2. Methods to assure reliability of components

Select subcomponents that are inherently reliable

Select standardized subcomponents rather than specialty subcomponents

Use any performance and reliability data that are available

De-rate parts or subcomponents in the component, or components in the system

Specify judicious safety margins for subcomponents

Test subcomponents under service conditions to "burn-in" or identify early failures

success depending on the part or subcomponent under consideration. Each method is briefly described below.

Selecting parts with inherent reliability takes advantage of known and proven manufacturing techniques, durability of parts that have proven themselves in the field, and compatibility of commercially available parts with the design intent. Inherent reliability is most often seen with passive components (i.e., non-powered items that do not require control signals to function, for example a pipe or tank, wire, etc.) versus active components. Active components do require input power (electricity, compressed air, etc.) and some form of control commands. Typically, passive components have failure rates that are several orders of magnitude lower than active components.

Standardized parts offer advantages of known behavior and maintenance needs, easily obtainable spare parts, and confidence in the ability to predict these traits in a new application with a high degree of certainty. An important example of this method is that the International Thermonuclear Experimental Reactor (ITER) design placed the safety burden on known, proven components rather than specialty components (Bartels, 1995). This was a prudent design choice that greatly helped the ITER project to show that the facility could meet and even exceed its strict safety and environmental design criteria.

The prudent designer always reviews the component operating experience to learn what has functioned well in the field and is worthy of repeated use, and what weaknesses or difficulties have been encountered in service that might be avoided in the future. Continuing to produce parts that show high numbers of failures in service would be counter-productive; it would be a business failure, or in this case it would mean having an experiment that operates for very short campaigns in a year. Often, small design improvements in system layout or interface with other systems can be made in the design stage that will yield better field performance. Another important part of operating experience feedback is noting the maintenance requirements for components and systems to better provide for these in a new facility. Providing adequate access and convenient 
apparatus (test ports or plug ins, etc.) will reduce maintenance time. Petroski (1985) points out that structural design engineering does not progress unless engineers look at failures in the field and improve designs to obviate future failure events. This cycle of "design-construct-operate-improve" noted in structural engineering is also true for other design disciplines.

De-rating parts or components means to use the item at conditions less demanding than the manufacturer's rated values. De-rating could be performed on mechanical, thermal, electrical or other stresses. For example, with electronic parts, de-rating often means operating at a reduced temperature or voltage below the manufacturer's quoted value. For mechanical parts, de-rating could mean operation at reduced duty cycle or reduced mechanical stress levels. De-rating increases the application reliability (Brummett, 1982). The de-rating approach is often seen in military equipment, particularly avionics and electronic devices; de-rating provides an extra margin of reliability in the field.

The designer must also choose a safety margin or safety factor. An overly large safety margin will increase system cost, may affect system performance, and may lead to increased operation costs in difficulty of maintenance, etc. An overly small safety margin leaves the system with little tolerance for upset events, can lead to excessive faults and downtime, and possibly the difficulty of a retrofit with a more robust component during the system lifetime. Therefore, a judicious safety factor that balances safety and economics must be found. Occasionally, the safety factor will be specified directly in a design code. For example, the American Society of Mechanical Engineers Boiler and Pressure Vessel (ASME B\&PV) Code gives safety factor direction, and the code has been adopted into US law (CFR, 2000). The ASME code has been reviewed for ITER applications (Majumdar, 1994; Karditsas, 1995). The safety factor may also be indirectly specified by an industry consensus design standard that suggests a particular approach or calculation method, such as for mechanical stresses, etc. The safety margin can also be added in by the choice of subcomponents. De-rating subcomponents typically increases the safety margin.

Part and component testing is an essential element in reliability during design. As workable designs are created, testing can show if there are any weaknesses in the prototype parts, the components, or the system that could be remedied by modifying the design. Testing should be as close to operating conditions as can be achieved. Some testing programs can be small and modest in scope, while others may be very large and detailed. An example of a large testing program is the magnetic fusion Large Coil Task (FED, 1988). Six superconducting magnet coils, each from a different manufacturer and using varying design approaches, were tested for operability and reliability. A more recent example is the Central Solenoid coil testing program under way for the ITER program at the Naka Japan design center (Matsukawa, 1999).

Table A-3 gives some qualitative values with a Likert-scale approach. These values will be used to assign reliability-in-design rankings to components. The ranking does not yield reliability in a quantitative sense. Individual values do not provide much insight; 
the ranking is most valuable when comparing two or more components or systems to each other.

Obviously, the higher the sum of ranking factors, the better the qualitative reliability. If some methods are not applicable for one design approach but can be used for another design approach, then normalizing by the number of applicable methods can be performed. In general, the design that takes advantage of all seven listed methods in the table will see the greatest benefits.

\section{System Reliability}

There are three well-known design methods available to increase system reliability. These methods are component redundancy, diversity, and overdesign for reliability (DOE, 1996). Redundancy means providing a second (or third, etc.) set of components that can complete the design function if the primary set suffers some sort of failure. Obviously, redundancy is an expensive approach to reliability since there are costs to purchase, house, install, test, and maintain multiple sets of components. For this reason, redundancy is typically only used for life safety, control of large quantities of radiologically or toxicologically hazardous material, control of large amounts of energy, or some other highly important design function. For redundancy to be effective, the redundant components must be independent from each other; physical separation, process separation, and support system separation. Otherwise, common cause failures could incapacitate all the sets of components. Common cause failures could be related to maintenance (i.e., a maintainer using mis-calibrated instrument on all units), testing (i.e., operators run equipment in a test without establishing proper conditions such as cooling), 
Table A-3. Ranking Factors for Qualitative Reliability in Design

Minimum number of parts in use

$$
\text { minimum }-3 \quad \text { few }-2 \text { many }-1 \text { extreme complexity }-0
$$

Inherently reliable parts in use

most or all $-3 \quad$ some $-2 \quad$ few $-1 \quad$ very few or none -0

Standardized parts in use

most or all $-3 \quad$ some $-2 \quad$ few $-1 \quad$ very few or none -0

Operating experience feedback in use

good usage $-3 \quad$ some usage $-2 \quad$ little usage $-1 \quad$ no usage -0

Part or component de-rating in use

good usage $-3 \quad$ some usage $-2 \quad$ little usage $-1 \quad$ no usage -0

Judicious safety margins in use
good usage -3
some usage -2
little usage -1
no usage -0

Part or subcomponent test program results in use
good usage -3
some usage -2
little usage -1
no usage -0

or the facility environment (i.e., water spray from pipe leakage in a room drenches two or more side-by-side units). An important event that highlighted redundancy issues was the Brown's Ferry fission power plant fire (Scott, 1976). Many of the redundant electrical cables were in the same cable trays, with one set of cables protected by conduits. Since the one set of cables were given extra protection, they were thought to have adequate physical separation. Unfortunately, the fire heat caused the cables within protective 
conduits to fail as well as the unprotected cables. Twenty-six cable trays, 117 conduits, and 1611 cables were damaged, and 628 of the cables were safety-related. That event proved the need for physical separation of redundant equipment.

Diversity is another approach to enhancing reliability in design. Component diversity means using a second (or third, etc.) set of components that can meet the design function, but these components are not all the same type or mirror images of each other. The primary and secondary components perform the same function, but are of different types. An engineering example is one train of a cooling water flow loop being powered by an electric motor centrifugal pump and the second, diverse, train being powered by a steam driven reciprocating pump. This arrangement is typically higher in capital cost than redundant systems, but is considered to be much more resilient to common cause failures. As well as the issues of purchasing, housing, and installing these components, diverse systems are very expensive to operate, since maintainers must have knowledge of multiple equipment types (perhaps requiring a larger maintenance staff) and appropriate varieties of spare parts must be kept in stock to minimize equipment downtime. Operators must also be familiar with different operating procedures for these different equipment items. Diversity is used for only the most important emergency functions of a system to ensure completion of the function. An example is brakes on an automobile. The primary brakes are typically hydraulic power-assisted brakes to all four wheels of a standard sedan. The diverse brake is the parking or emergency brake, which is a mechanical wire system to only the rear wheels. The parking brake will operate to brake the automobile even when there is a loss of hydraulic power.

Overdesign for reliability means that there is only one primary set of components, and they are built to be very robust. Large safety factors are used so that the part can function through all foreseeable conditions. An example of overdesign is a liquid storage tank. Instead of redundancy (i.e., double walls of the same material), or diversity (i.e., double walls of differing materials), the single wall tank is built to be very thick-walled so that it will function through any operating or accident scenario. The very thick walls mean that corrosion concerns are reduced, the vessel can withstand high pressure, and other environmental assaults. Since overdesign can often lead the designer to use specialty parts, it is not a particularly favored design technique. The overdesigned part can be expensive and must be qualified for use by a specialized testing program. Testing such parts may be exhaustive and expensive. Periodic inspections, such as radiography, are usually expensive since the parts are very thick-walled.

Some other factors also affect the lifetime reliability. Design provisions for field maintenance, including preventive and corrective maintenance, will affect the availability of repairable components. Maintenance access will also affect the availability of a system because of any difficulty experienced in replacing a failed part adds to the system downtime. Inspection frequency or testing frequency provides information on how the component or system is aging. Standby units require testing at some time interval to verify that they have not degraded and can function when called upon. Too frequent testing can wear out standby components, and too infrequent testing does not verify operability (i.e., that the system will operate when demanded to operate). Operational 
units require inspection to verify that they are not degrading while in service; or if they are known to degrade, that the process is being monitored so the component can be removed from service prior to failure. An example of monitoring is periodic inspection of pipe wall thickness. Erosion thinning can reduce pipe wall thickness and allow a pipe to fail while the contained fluid is at design pressure and temperature conditions. Keeping track of thinning allows the staff to replace the pipe before the walls become too thin. The overall system or facility may have an availability requirement that places restrictions on allowable repair time or replacement time, and may mean that more than one system train is needed to meet the requirement. The system mission may change over its lifetime, so flexibility and margin must be considered during the design to account for likely evolutions over the facility lifetime. An integrated plan for the system or facility evolution helps the designer plan for future changes. An example of this flexibility would be to include extra ports in a vacuum vessel design in case extra diagnostics were needed later in the operational lifetime of the experiment. Of course, limiting the number of ports helps to increase the vacuum vessel structural integrity against overpressure events, so ports are added with great discretion. There are also other flexibility issues that the designer must consider.

\section{Reliability for Tokamak In-vessel Components}

An initial look at the design and operating conditions for in-vessel components shows us that there are not many applications similar to magnetic fusion that might provide operating experience data for quantitative reliability. Inference methods have borrowed data from fission reactors (Marshall, 1994), but these data are often held suspect by designers because of differences between the types of reactors. Notable differences are neutron energy spectrum and fluence, temperature and pressure of coolant, material alloy, and duty factor. There are other differences, but those listed are the main contrasts raised in the fusion community. Data on high heat flux components in aerospace applications, such as rocket nozzle cooling, are not easily found and are not very applicable because of differences in coolants, mission lifetime, operating temperatures and pressures, and the absence of significant ionizing radiation exposure in aerospace applications. The only similar application identified thus far is beam stop cooling in particle accelerators, and the aluminum alloys possible for accelerators (see Hanna, 1991) vary from those needed in magnetic fusion. There is little quantitative data found in the literature on these components. If a beam stop were to have a fault, the accelerator would have downtime and either remote or possibly use hands-on maintenance would be used to change out the beam stop.

Schultz (1981) made a qualitative approach for assessing first wall reliability. Schultz' features are in addition to the qualitative design reliability factors already discussed. The desirable features in a first wall were listed as:

1. Redundancy. A failure of part of the armor would not require reactor shut down.

2. Clearance. Maximize the distance between the plasma-facing wall and the coolant, to provide an erosion margin. 
3. Small toroidal dimensions. Small dimensions transverse to the minor radius are desirable to reduce the thermal and magnetic stresses from reactor operation.

4. Maintainability. All parts would be rapidly replaceable.

5. Vacuum integrity. Moveable components (i.e., limiter blades) should be removable without breaking vacuum.

6. Renewable surfaces. If possible, high erosion parts should have a continuous feed mechanism.

Some design enhancements have been incorporated since the generation of that list of features. For example, considering feature 1, the ITER design used a first wall and a vacuum vessel cooling system. If the in-vessel cooling were lost, the vacuum vessel cooling system could still remove the decay heat from in-vessel components. So, the first feature, redundancy of in-vessel components, is not as important as it once was. Nonetheless, failures of the in-vessel components must still be tolerated. Pieces of wall armor must not enter the plasma, or they would likely cause a density-limit disruption. The wall armor must protect the substrate from plasma conditions, so losses of tiles cannot be tolerated.

Feature two, clearance, or erosion margin, is still an important aspect for design. Tokamaks have begun plasma spraying the solid walls to provide a coating of low atomic number material next to the plasma. Diborane (Mueller, 1991) and decaborane (Saidoh, 1993) are used to deposit boron, and beryllium tiles have been used (Deksnis, 1997). Plasma sprayed beryllium as been tested as well (Castro, 1998). As mentioned earlier, there is a tradeoff between erosion allowance and tile thickness to allow adequate heat transfer.

Feature 3, the small toroidal dimensions issue, is no longer as important since designers are now more aware of the magnitude of electromagnetic forces and the hazards they present. The forces are large and cannot be dismissed, but they are treated adequately in design so that overstress failures do not result and there is no loss of material useful lifetime due to these stress loads.

Feature 4, maintainability, is still a very important issue. Fusion power must be economically competitive with other forms of power generation, and on-line time producing electricity is an important part of that competitiveness (Cadwallader, 1999). Successfully maintainable designs mean that on-line time is maximized. An important issue to remember is the learning curve for operations. The initial fission power plants had high goals for availability, but the first outages for refueling and inspections were up to 6 months in duration. Some matured fission power plants can now change fuel and restart within three weeks, nearly all plants can change fuel in less than 2 months. As fusion power plants matured, a similar learning factor is expected. Present estimates of downtime for outages may be reasonable for first efforts, but do not reflect improvements in future performance. 
Feature 5, vacuum integrity, is not as important as it once was since components are now more resilient; fewer components require breaking vacuum until scheduled replacement sessions.

The last feature, renewable surfaces, is very interesting. When Schultz made the list of features nearly twenty years ago, he concluded that renewable surfaces might not be achievable, although such surfaces had been discussed for the UWMAK conceptual design (Badger, 1973). Now, the fusion community is examining solid wall restoration with plasma spraying or chemical vapor deposition of beryllium or boron, and the liquid wall concept from inertial fusion may provide a self-renewing wall during plant operation. These features can be used as criteria to evaluate candidate designs. Given how the state of knowledge and design has progressed, the Schultz list is amended as such:

1 Fault tolerance. This evaluation criteria is an analysis of how well the in-vessel components can tolerate a failure in a portion of the system.

2 Surface damage tolerance. This evaluation criteria is a measure of erosion (from the plasma facing side and from any walls in contact with flowing coolant) or other timein-service degradations and how resilient the wall is to the damage mechanisms.

3 Durability. In this case, durability is defined as the tolerance of the candidate design to off-normal stresses, such as electromagnetic forces, vibration, and thermal gradient induced forces.

4 Maintainability. All parts would be rapidly replaceable. Downtime would be minimized by design. The smaller the yearly downtime, the more successful the design.

The two desirable features of vacuum integrity and renewable surfaces in the original Schultz list were removed. The vacuum integrity was removed since there is less need to break vacuum with current designs, and much less concern over that issue. Experience with the Joint European Torus (JET) has shown that remote handling can be performed without venting for manned entry; the vessel is re-commissioned more quickly and easily from a nitrogen atmosphere without manned entry into the vessel. The renewable surface feature was removed since a liquid wall (renewable) design is now under consideration and will be compared to the solid wall using the other features given on the list. Other ideas by Schultz were renamed for clarity or for broader applicability.

A candidate comparison of an ITER-like solid wall design and a conceptual liquid wall design using those four evaluation criteria is given in the body of this report. 


\section{Appendix A References}

Badger, 1973. B. Badger et al., UWMAK-I, A Wisconsin Toroidal Fusion Reactor Design, UWFDM-68, University of Wisconsin Nuclear Engineering Department, November 1973.

Bartels, 1995. H.-W. Bartels et al., "In-vessel Safety in the ITER-EDA Design," Fusion Technology 1994, Proceedings of the $18^{\text {th }}$ Symposium on Fusion Technology, Karlsruhe, Germany, 22-26 August 1994, Elsevier, 1995, pages 1461-1464.

Bellcore, 1992. Reliability Prediction Procedure for Electronic Equipment, Technical Reference TR-NWT-000332, Bellcore Communications Research, September 1992.

Brummett, 1982. S. L. Brummett et al., Reliability Parts Derating Guidelines, RADC-T82-177, accession number AD-A120 367, Rome Air Development Center, June 1982.

Cadwallader, 1996. L. C. Cadwallader and T. D. Marshall, "Component Reliability Data Estimation for Fusion Safety and Risk Assessment," Proceedings of the International Topical Meeting on Probabilistic Safety Assessment (PSA '96), Park City, UT, September 29-October 3, 1996, volume 1, pages 637-648.

Cadwallader, 1999. L. C. Cadwallader and D. A. Petti, “A Review of Availability Growth in Energy Production Technologies," Proceedings of the $18^{\text {th }}$ Symposium on Fusion Engineering, October 25-29, 1999, Albuquerque, New Mexico, IEEE, pages 585-588.

Caplen, 1972. R. Caplen, A Practical Approach to Reliability, Business Books Limited, London, ISBN 022066809 4, 1972.

Castro, 1998. R. G. Castro et al., "Fabrication and high heat flux testing of plasma sprayed beryllium ITER first wall mock-ups," Journal of Nuclear Materials, 258$\underline{263}, 1998$, pages 252-257.

CCPS, 2000. Guidelines for Chemical Process Quantitative Risk Analysis, second edition, Center for Chemical Process Safety, American Institute of Chemical Engineers, New York, ISBN 0-8169-0720-X, 2000, pages 561-563.

CFR, 2000. 10CFR50.55a. Title 10, Energy, of the Code of Federal Regulations, Part 50, Domestic Licensing of Production and Utilization Facilities, section 55a, Codes and Standards, January 1, 2000.

Deksnis, 1997. E. B. Deksnis et al., "Beryllium plasma-facing components: JET Experience," Fusion Engineering and Design, 37, 1997, pages 515-530. 
DOE, 1996. Safety of Magnetic Fusion Facilities: Requirements, DOE-STD-6002-96, US Department of Energy, May 1996.

FED, 1988. “The IEA Large Coil Task," Fusion Engineering and Design, 7, 1988, pages 75-94.

Hanna, 1991. B. Hanna, C. Crawford, "Construction of a New Tevatron Collider Beam Abort Dump," Conference Record of the 1991 IEEE Particle Accelerator Conference, San Francisco, CA, May 6-9, 1991, volume 2, pages 970-972.

IEC, 1985. Analysis Techniques for System Reliability - Procedure for Failure Mode and Effects Analysis (FMEA), IEC 60812, International Electrotechnical Commission, July 1985.

IEEE, 1987. IEEE Guide for General Principles of Reliability Analysis of Nuclear Power Generating Station Safety Systems, ANSI/IEEE Std 352-1987, American National Standards Institute, October 1987.

Karditsas, 1995. P. J. Karditsas, "Structural analysis and design against failure of fusion power plant components with special reference to pulsed operation," Fusion Engineering and Design, 30, 1995, pages 307-323.

Majumdar, 1994. S. Majumdar, "Design standard issues for ITER in-vessel components," Fusion Engineering and Design, 29, 1994, pages 158-163.

Marshall, 1994. T. D. Marshall and L. C. Cadwallader, In-Vessel ITER Tubing Failure Rates for Selected Materials and Coolants, EGG-FSP-10928, Idaho National Engineering Laboratory, March 1994.

Matsukawa, 1999. M. Matsukawa et al., "Preparations for pulse operation tests of the ITER CS model coil using the JT-60 power supply," IEEE Transactions on Applied Superconductivity, 10, 1999, pages 1410-1413.

MIL, 1991. Military Handbook 217F, Reliability Prediction of Electronic Equipment, MIL HDBK 217F, US Department of Defense, December 1991.

Mueller, 1991. D. Mueller et al., "Discharge Cleaning on Tokamak Fusion Test Reactor after Boronization," Journal of Vacuum Science and Technology, Part A, 9, 1991, pages 2713-2715.

NASA, 1988. Instructions for Preparation of Failure Modes and Effects Analysis (FMEA) and Critical Items List (CIL), NASA NSTS 22206, National Aeronautics and Space Administration, National Shuttle Transportation System document, August 1988. 
NSWC, 1992. Handbook of Reliability Prediction Procedures for Mechanical Equipment, AD-A273 174, CARDEROCKDIV-NSWC-92/LO1, Naval Surface Warfare Center, Bethesda, MD, May 1992.

Petroski, 1985. H. Petroski, To Engineer is Human, the Role of Failure in Successful Design, St. Martin's Press, New York, ISBN 0-312-80680-9, 1985.

Pinna, 1998. T. Pinna, R. Caporali, G. Cambi, L. Burgazzi, A. Poucet, and M. T. Porfiri, "Failure mode and effect analysis on ITER heat transfer systems," Fusion

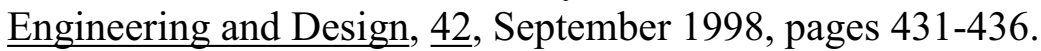

SAE, 1995. Potential Failure Mode and Effects Analysis in Design (Design FMEA) Potential Failure Mode and Effects Analysis in Manufacturing and Assembly Processes (Process FMEA) Reference Manual, SAE J1739, Society of Automotive Engineers, June 1995.

Saidoh, 1993. M. Saidoh et al., "A Boronization System in the JT-60U Tokamak: Application of a New Method Using a Less Hazardous Substance," Fusion Engineering and Design, 22, 1993, pages 271-275.

Schultz, 1981. J. H. Schultz, "Towards a Strategy of Reliable Fusion First Wall Design," Proceedings of the $9^{\text {th }}$ Symposium on Engineering Problems of Fusion Research, Chicago, Illinois, October 26-29, 1981, volume II, IEEE, pages 1406-1409.

Scott, 1976. R. L. Scott, "Browns Ferry Nuclear Power-Plant Fire on Mar. 22, 1975," Nuclear Safety, 17, 1976, pages 592-611. 